\title{
2013s-01
}

\section{A Model-Free Measure of Aggregate Idiosyncratic Volatility and the Prediction of Market Returns}

\author{
René Garcia, Daniel Mantilla-García, Lionel Martellini
}

\begin{tabular}{c}
\hline Série Scientifique \\
Scientific Series
\end{tabular}

\author{
Montréal \\ Janvier 2013
}

(C) 2013 René Garcia, Daniel Mantilla-García, Lionel Martellini. Tous droits réservés. All rights reserved. Reproduction partielle permise avec citation du document source, incluant la notice $($.

Short sections may be quoted without explicit permission, if full credit, including (C) notice, is given to the source.
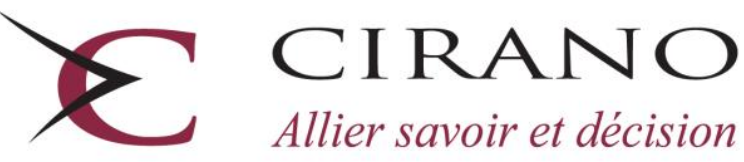

Allier savoir et décision

Centre interuniversitaire de recherche en analyse des organisations 


\section{CIRANO}

Le CIRANO est un organisme sans but lucratif constitué en vertu de la Loi des compagnies du Québec. Le financement de son infrastructure et de ses activités de recherche provient des cotisations de ses organisations-membres, d'une subvention d'infrastructure du Ministère du Développement économique et régional et de la Recherche, de même que des subventions et mandats obtenus par ses équipes de recherche.

CIRANO is a private non-profit organization incorporated under the Québec Companies Act. Its infrastructure and research activities are funded through fees paid by member organizations, an infrastructure grant from the Ministère du Développement économique et régional et de la Recherche, and grants and research mandates obtained by its research teams.

\section{Les partenaires du CIRANO}

\section{Partenaire majeur}

Ministère du Développement économique, de l'Innovation et de l'Exportation

\section{Partenaires corporatifs}

Autorité des marchés financiers

Banque de développement du Canada

Banque du Canada

Banque Laurentienne du Canada

Banque Nationale du Canada

Banque Scotia

Bell Canada

BMO Groupe financier

Caisse de dépôt et placement du Québec

Fédération des caisses Desjardins du Québec

Financière Sun Life, Québec

Gaz Métro

Hydro-Québec

Industrie Canada

Investissements PSP

Ministère des Finances du Québec

Power Corporation du Canada

Rio Tinto Alcan

State Street Global Advisors

Transat A.T.

Ville de Montréal

Partenaires universitaires

École Polytechnique de Montréal

HEC Montréal

McGill University

Université Concordia

Université de Montréal

Université de Sherbrooke

Université du Québec

Université du Québec à Montréal

Université Laval

Le CIRANO collabore avec de nombreux centres et chaires de recherche universitaires dont on peut consulter la liste sur son site web.

Les cahiers de la série scientifique (CS) visent à rendre accessibles des résultats de recherche effectuée au CIRANO afin de susciter échanges et commentaires. Ces cahiers sont écrits dans le style des publications scientifiques. Les idées et les opinions émises sont sous l'unique responsabilité des auteurs et ne représentent pas nécessairement les positions du CIRANO ou de ses partenaires.

This paper presents research carried out at CIRANO and aims at encouraging discussion and comment. The observations and viewpoints expressed are the sole responsibility of the authors. They do not necessarily represent positions of CIRANO or its partners. 


\title{
A Model-Free Measure of Aggregate Idiosyncratic Volatility and the Prediction of Market Returns"
}

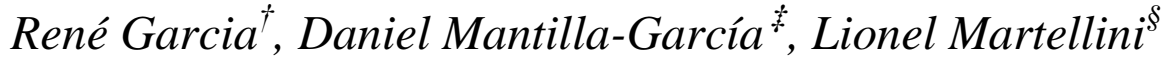

\section{Résumé / Abstract}

In this paper, we formally show that the cross-sectional variance of stock returns is a consistent and asymptotically efficient estimator for aggregate idiosyncratic volatility. This measure has two key advantages: it is model-free and observable at any frequency. Previous approaches have used monthly model based measures constructed from time series of daily returns. The newly proposed crosssectional volatility measure is a strong predictor for future returns on the aggregate stock market at the daily frequency. Using the cross-section of size and book-to-market portfolios, we show that the portfolios' exposures to the aggregate idiosyncratic volatility risk predict the cross-section of expected returns.

Mots clés : Aggregate idiosyncratic volatility, cross-sectional dispersion, prediction of market returns.

\footnotetext{
* A previous version of this paper circulated under the title: 'Idiosyncratic Risk and the Cross-Section of Stock Returns". We are grateful to an anonymous referee for useful and insightful comments. We also thank Michel Crouhy, Robert Engle, Stéphane Gregoir, Abraham Lioui, Harrison Hong, Frederic Smadja, Stoyan Stoyanov, Georges Tauchen, Stéphane Tyc, Vijay Vaidyanathan, Volker Ziemann, as well as seminar and conference participants at EDHEC Business School, the Financial Econometrics Conference (Toulouse), the Financial Econometrics Workshop (SMU), the Conference in Asset and Risk Management in the Aftermath of the Financial Crisis (HEC Lausanne), for useful discussions and comments. This research has benefited from the support of the Chair "Produits Structures et Produits Dérivés", Fédération Bancaire Française. The author for correspondence is René Garcia. The address and phone number for all three authors are: EDHEC Business School, 393, Promenade des Anglais BP 311606202 Nice cedex 3 - France. Phone: + 33 (0)4 93189966.

$\dagger$ EDHEC Business School, CIREQ and CIRANO, rene.garcia@edhec.edu

* Koris International, EDHEC-Risk Institute, daniel.mantilla@koris-intl.com

${ }^{\S}$ EDHEC Business School, EDHEC-Risk Institute, lionel.martellini@edhec.edu
} 


\section{Introduction}

The recent financial literature has paid considerable attention to idiosyncratic volatility. Campbell, Lettau, Malkiel, and Xu (2001) and Malkiel and Xu (2002) document that idiosyncratic volatility increased over time, while Brandt, Brav, Graham, and Kumar (forthcoming) show that this trend completely reversed itself by 2007, falling below pre-1990s levels and suggest that the increase in idiosyncratic volatility through the 1990s was not a time trend but rather an "episodic phenomenon". Bekaert, Hodrick, and Zhang (forthcoming) confirm that there is no trend both for the United States and other developed countries. A second fact about idiosyncratic volatility is also a source of contention. Goyal and Santa-Clara (2003) put forward that idiosyncratic volatility has forecasting power for future excess returns, while Bali, Cakici, Yan, and Zhang (2005) and Wei and Zhang (2005) find that the positive relationship is not robust to the sample chosen. Finally, while some economic theories suggest that idiosyncratic volatility should be positively related to expected returns, Ang, Hodrick, Xing, and Zhang (2006) find that stocks with high idiosyncratic volatility have low average returns.

An underlying issue in all these studies is the measurement of idiosyncratic volatility. Campbell et al. (2001) use a value-weighted sum of individual firm idiosyncratic variances, computed as the variances of residuals of differences between individual firm returns and the return of an industry portfolio to which the firm belongs. ${ }^{1}$ In addition to this measure, Bekaert et al. (forthcoming) use the individual firm residuals of a standard Fama and French three-factor model to compute a value-weighted aggregate idiosyncratic volatility. ${ }^{2}$

We revisit the issues regarding the dynamics and forecasting power of idiosyncratic variance by using instead the cross-sectional dispersion of stock returns. Through central limit arguments, we provide the formal conditions under which the cross-sectional variance (CSV) of stock returns asymptotically converges towards the average idiosyncratic variance. ${ }^{3}$

\footnotetext{
${ }^{1}$ This amounts to imposing unit beta restrictions in an industry-market model.

${ }^{2}$ This is also the approach followed in Ang et al. (2006).

${ }^{3}$ Goyal and Santa-Clara (2003) argue informally that their measure can be interpreted as a measure of
} 
One key advantage of this measure is obviously its observability at any frequency, while the previous approaches have used monthly measures based on time series of daily returns. A second important feature is that this measure is model-free, since we do not need to obtain residuals from a particular model to compute it.

We confirm empirically that the cross-sectional variance is an excellent proxy for the idiosyncratic variance obtained from the CAPM or the Fama-French models, as done in the previous literature. Correlations between the CSV measure and the model-based measures estimated monthly are always above $99 \%$, whether we consider equally-weighted or capitalization-weighted measures of idiosyncratic variance.

On the debate about predictability of aggregate returns by the idiosyncratic variance, we first verify empirically that the CSV measure leads to the same conclusions that other studies (in particular Goyal and Santa-Clara (2003) and Bali et al. (2005)) have reported at the monthly frequency. Then, we report new results at the daily frequency. Specifically, we show that the predictive power of idiosyncratic volatility is much stronger both quantitatively and statistically at the daily frequency than at the monthly frequency. This relationship is robust to the inclusion of index return variance, option-implied variance and index realized variance as additional variables in the predictive regressions.

We find that the relation is much stronger and stable across periods between the equallyweighted measure of aggregate idiosyncratic volatility and the returns on the equallyweighted index than for the market-cap weighted equivalents. Economic sources of heterogeneity between firms, as diverse as they can be, are better reflected in an equally weighted measure, all other things being equal. This argument is consistent with previous findings in Bali et al. (2005), who argue that the relationship between equal-weighted average idiosyncratic risk and the market-cap weighted index on the sample ending in 1999:12 is mostly driven by small stocks traded in the NASDAQ.

cross-sectional dispersion of stock returns, but do not establish a formal link between the two. Allen and Bali (2007) use cross-sectional moments of equity returns for financial institutions to measure catastrophic and operational risks. 
Finally, we unveil an asymmetry in the relationship between idiosyncratic variance and returns and show that the predictive power of specific risk is substantially increased when a cross-sectional measure of idiosyncratic skewness is added as explanatory variable.

Using a Fama-MacBeth procedure with several sets of portfolios, we find support for a positive and significant price of risk for the exposure to the idiosyncratic variance risk. This is consistent with the asset pricing literature, since most theories support a positive relation between idiosyncratic risk and expected returns (see in particular Levy (1978), Merton (1987), Malkiel and Xu (2002), Campbell et al. (2001), and Guo and Savickas (2008)).

The rest of the paper is organized as follows. In Section II, we provide a formal argument for choosing the cross-sectional variance of returns as a measure of average idiosyncratic volatility, explore its asymptotic and finite-distance properties, and compare it to other measures formerly selected in the literature. Section III provides an empirical implementation of the concept, again in comparison with other measures, and studies its relation with macroeconomic variables. In Section IV, we provide new results on the predictability of returns by idiosyncratic volatility, as well as idiosyncratic skewness. Section V focuses on the analysis of the cross-sectional relationship between idiosyncratic risk and expected returns. Section VI concludes and an appendix collects proofs.

\section{The Cross-sectional Variance as a Measure of Id- iosyncratic Variance}

Let $N_{t}$ be the total number of stocks in a given universe at day $t$, and assume with no loss of generality a conditional single factor model for excess stock returns. ${ }^{4}$ That is, we assume that for all $i=1, \ldots, N_{t}$, the return on stock $i$ in excess of the risk-free rate can be written

\footnotetext{
${ }^{4}$ Assuming a single factor structure is done for simplicity of exposure only and the results below can easily be extended to a multi-factor setting.
} 


$$
r_{i t}=\beta_{i t} F_{t}+\varepsilon_{i t}
$$

where $F_{t}$ is the factor excess return at time $t, \beta_{i t}$ is the beta of stock $i$ at time $t$, and $\varepsilon_{i t}$ is the residual, with $E\left(\varepsilon_{i t}\right)=0$ and $\operatorname{cov}\left(F_{t}, \varepsilon_{i t}\right)=0$. We assume that the factor model under consideration is a strict factor model, that is $\operatorname{cov}\left(\varepsilon_{i t}, \varepsilon_{j t}\right)=0$ for $i \neq j^{5}$.

Given $T$ observations of the stock returns and the factor return, one can use the residuals of the regression to obtain a measure of the idiosyncratic variance of asset $i$ by: $\sigma_{i}^{2}=\frac{1}{T} \sum_{t=1}^{T} \varepsilon_{i t}^{2}$. An aggregate measure of idiosyncratic variance over the $T$ observations (say a month) can be obtained by averaging across assets such individual idiosyncratic variance estimates. This is the approach that has been followed by most related papers with observations of the returns at a daily frequency to compute monthly idiosyncratic variances.

We propose instead to measure at each time $t$ the cross-sectional variance of observed stock returns. Using formal central-limit arguments, we show that, under mild simplifying assumptions, this cross-sectional measure provides a very good approximation of the average idiosyncratic variance. Moreover, it offers two main advantages: it can be computed directly from observed returns, with no need to estimate other parameters such as betas, and it is readily available at any frequency and for any universe of stocks.

\footnotetext{
${ }^{5}$ This assumption is made in the single index or diagonal model of Sharpe (1963) and in the derivation of the APT in Ross (1976). The very definition of idiosyncratic risk relies on the assumption of orthogonal residuals: assuming that the model is the "true" factor model implies that the "true" idiosyncratic risk is the one measured with respect to that model, which in turn implies that no commonalities should be left after controlling for the common factor exposure.
} 


\section{A Measuring the Cross-Sectional Variance}

Let $\left(w_{t}\right)_{t \geq 0}$ be a given weight vector process. The return on the portfolio defined by the weight vector process $\left(w_{t}\right)$ is denoted by $r_{t}^{\left(w_{t}\right)}$ and given by:

$$
r_{t}^{\left(w_{t}\right)}=\sum_{i=1}^{N_{t}} w_{i t} r_{i t}
$$

We restrict our attention to non-trivial weighting schemes, ruling out situations such that the portfolio is composed by a single stock. We also restrict the weights to be positive at every point in time. Hence, a weighting scheme $\left(w_{t}\right)$ is a vector process which satisfies $0<w_{i t}<1 \forall i, t$. The cross-sectional variance measure is defined as follows.

Definition ( $\boldsymbol{C S} \boldsymbol{V})$ : The cross-sectional variance measure under the weighting scheme $\left(w_{t}\right)$, denoted by $\boldsymbol{C S} \boldsymbol{V}_{t}^{\left(w_{t}\right)}$, is given by

$$
C S V_{t}^{\left(w_{t}\right)}=\sum_{i=1}^{N_{t}} w_{i t}\left(r_{i t}-r_{t}^{\left(w_{t}\right)}\right)^{2} .
$$

A particular case of interest is the equally-weighted CSV, denoted by $C S V_{t}^{E W}$ and corresponding to the weighting scheme $w_{i t}=1 / N_{t} \forall i, t$ :

$$
C S V_{t}^{E W}=\frac{1}{N_{t}} \sum_{i=1}^{N_{t}}\left(r_{i t}-r_{t}^{E W}\right)^{2}
$$

where $r_{t}^{E W}$ is the return on the equally-weighted portfolio.

Another important weighting scheme is the capitalization weighting scheme. If we denote by $c_{i t}$ the market capitalization of stock $i$ at the beginning of the month corresponding to day $t, C_{t}=\sum_{i=1}^{N_{t}} c_{i t}$ the total market capitalization and $r_{t}^{C W}$ the return on the market capitalization-weighted portfolio, the cap-weighted CSV, denoted by $C S V^{C W}$, is defined as:

$$
C S V_{t}^{C W}=\sum_{i=1}^{N_{t}} w_{i t}^{C W}\left(r_{i t}-r_{t}^{C W}\right)^{2}
$$


where $w_{i t}^{C W}=\sum_{i=1}^{N_{t}} \frac{c_{i t}}{C_{t}}$.

For any given weighting scheme (in particular EW or CW), the corresponding crosssectional measure is readily computable at any frequency from observed returns. This stands in contrast with the previous approaches that have used monthly measures based on time series regressions on daily returns. The second important feature of the CSV is its model-free nature, since we do not need to specify a particular factor model to compute $\mathrm{it}^{6}$.

\section{B A Formal Relationship between CSV and Idiosyncratic Vari- ance}

The following proposition establishes a formal link between CSV and idiosyncratic variance. It is an asymptotic result $\left(N_{t} \rightarrow \infty\right)$ obtained under the assumptions of homogeneous betas and residual variances across stocks. These assumptions will be relaxed later on.

Proposition 1 (CSV as a proxy for idiosyncratic variance - asymptotic results):

Assume $\beta_{i t}=\beta_{t}=1 \forall i$ (homogeneous beta assumption) and $E\left(\varepsilon_{i t}^{2}\right)=\sigma_{\varepsilon}^{2}(t) \forall i$ (homogeneous residual variance assumption), then for any strictly positive weighting scheme satisfying for all dates $t$ the condition $\sum_{i=1}^{N_{t}} w_{i t}^{2}=O\left(\frac{1}{N_{t}}\right)$, we have that:

$$
C S V_{t}^{\left(w_{t}\right)}=\sum_{i=1}^{N_{t}} w_{i t}\left(r_{i t}-r_{t}^{\left(w_{t}\right)}\right)^{2} \underset{N_{t} \rightarrow \infty}{\longrightarrow} \sigma_{\varepsilon}^{2}(t) \text { almost surely. }
$$

Proof See Appendix A.

This result draws a formal relationship between the dynamics of the cross-sectional dispersion of realized returns and the dynamics of aggregate idiosyncratic variance. Note

\footnotetext{
${ }^{6}$ While Goyal and Santa-Clara (2003) and Wei and Zhang (2005)consider the equally-weighted CSV in conjunction with other measures, they do not provide a thorough discussion about the conditions under which it can be interpreted as a proxy for idiosyncratic variance nor its empirical validity in the data, as we provide in this paper.
} 
that the asymptotic result $C S V_{t}^{\left(w_{t}\right)} \longrightarrow \sigma_{\varepsilon}^{2}(t)$ holds for any weighting scheme that satisfies the condition $\sum_{i=1}^{N_{t}} w_{i t}^{2}=O\left(\frac{1}{N_{t}}\right)^{7}$. This condition, which translates into the existence of a constant $C_{t}$ such that $\sum_{i=1}^{N_{t}} w_{i t}^{2} \leq \frac{C_{t}}{N_{t}}$, is trivially satisfied for the equally-weighted scheme by taking $C_{t}=1$ for all $t^{8}$. Intuitively, the condition rules out cases where portfolios show an extreme level of concentration. Therefore, the case of the cap-weighting scheme is more complex, since in principle the condition $\sum_{i=1}^{N_{t}} w_{i t}^{2}=O\left(\frac{1}{N_{t}}\right)$ may not hold, depending on how market capitalization weights evolve as the number of stocks increases. In the empirical analysis that follows, we actually focus on the equally-weighted scheme, and we only consider the cap-weighted scheme for comparison purposes. Formal justification for our focus on the equally-weighted scheme is provided in the next section, where we show that the $C S V^{E W}$ is the best estimator for idiosyncratic variance within the class of CSV obtained under a strictly positive weighting scheme.

\section{Properties of CSV as an Estimator for Idiosyncratic Variance}

First, we derive in Proposition 2 the bias and the variance of the CSV as an estimator of idiosyncratic variance. Then we study asymptotic limits as the number of firms grows large and conclude that the equally-weighted CSV is the best among all positively-weighted estimators.

\section{Proposition 2 (Bias and variance of $C S V$ ):}

Maintaining the homogenous beta assumption $\left(\beta_{i t}=\beta_{t}=1 \forall i, t\right)$ and the homogeneous residual variance assumption $\left(E\left(\varepsilon_{i t}^{2}\right)=\sigma_{\varepsilon}^{2}(t) \forall i\right)$, for any strictly positive weighting scheme, we have that:

$$
E\left[C S V_{t}^{\left(w_{t}\right)}\right]=\sigma_{\varepsilon}^{2}(t)\left(1-\sum_{i=1}^{N_{t}} w_{i t}^{2}\right)
$$

\footnotetext{
${ }^{7}$ Of course, at finite distance, different weighting schemes will generate different proxies for idiosyncratic variance.

${ }^{8}$ See Cuzick (1995) or Sung (2002) for slightly weaker conditions.
} 
To analyze the variance of the CSV estimator, we further make the assumption of multivariate normal residuals $\varepsilon \sim N\left(0, \Sigma^{\varepsilon}\right)$, where $\Sigma^{\varepsilon}$ denotes the variance covariance matrix of the residuals. Under this additional assumption, we obtain:

$$
\operatorname{Var}\left[C S V_{t}^{\left(w_{t}\right)}\right]=2 \sigma_{\varepsilon}^{2}(t)\left(\left(\sum_{i=1}^{N_{t}} w_{i t}^{2}\right)^{2}+\sum_{i=1}^{N_{t}} w_{i t}^{2}-2 \sum_{i=1}^{N_{t}} w_{i t}^{3}\right)
$$

Proof See Appendix B for a proof in the slightly more general case when the homogeneous specific variance assumption has been relaxed.

Hence the CSV is a biased estimator for idiosyncratic variance, with a bias given by the

multiplicative factor $\left(1-\sum_{i=1}^{N_{t}} w_{i t}^{2}\right)$, which can be easily corrected for since it is available in explicit form. In the end, the bias and variance of the CSV appear to be minimum for the EW scheme, which corresponds to taking $w_{i t}=1 / N_{t}$ at each date t. It is easy to see that this bias disappears and the variance tends to zero for the equally-weighted scheme when the number of stocks grows infinitely large, as explained in the following proposition.

\section{Proposition 3 (Properties of the equally-weighted CSV)}

The bias and variance of the EW CSV as an estimator for specific variance disappear in the limit of an increasingly large number of stocks:

$$
\begin{aligned}
& E\left[C S V_{t}^{E W}\right] \underset{N_{t} \rightarrow \infty}{\longrightarrow} \sigma_{\varepsilon}^{2}(t) . \\
& \operatorname{Var}\left(C S V_{t}^{E W)}\right)_{N_{t} \rightarrow \infty}^{\longrightarrow} 0 .
\end{aligned}
$$

Proof See Appendix B for a proof in the slightly more general case when the homogeneous specific variance assumption has been relaxed.

The equally-weighted $C S V$ thus appears to be a consistent and asymptotically efficient estimator for idiosyncratic variance. As such, it is the best estimator in the class of CSV estimators defined under any positive weighting scheme, and it dominates in particular the cap-weighted CSV as an estimator for idiosyncratic variance. If we relax the homogeneous 
residual variance assumption, we still obtain that the CSV appears to be an asymptotically unbiased estimator for the average idiosyncratic variance of the stocks in the universe (see Appendix B). Hence, the assumption of homogeneous residual variances comes with no loss of generality.

\section{Relaxing the Homogeneity Assumption for Factor Loadings}

Relaxing the homogeneous beta assumption involves a bias that remains strictly positive even for an infinite number of stocks and an equal-weighting scheme. We characterize this bias in the next proposition in order to gauge its magnitude for given models of returns.

Proposition 4 Bias of CSV as an estimator for average idiosyncratic variance in the presence of heterogenous betas: Relaxing the assumptions $\beta_{i t}=\beta_{t}=1 \forall i, t$ (homogeneous beta assumption) we have, for any strictly positive weighting scheme:

$$
E\left[C S V_{t}^{\left(w_{t}\right)}\right]=\sum_{i=1}^{N_{t}} w_{i t} \sigma_{\varepsilon_{i}}^{2}(t)-\sum_{i=1}^{N_{t}} w_{i t}^{2} \sigma_{\varepsilon_{i}}^{2}(t)+E\left[F_{t}^{2} C S V_{t}^{\beta}\right]
$$

where $C S V_{t}^{\beta}$ denotes the cross-sectional variance of stock betas:

$$
C S V_{t}^{\beta}=\sum_{i=1}^{N_{t}} w_{i t}\left(\beta_{i t}-\sum_{j=1}^{N_{t}} w_{j t} \beta_{j t}\right)^{2}
$$

Proof See Appendix C.

The first term $\sum_{i=1}^{N_{t}} w_{i t} \sigma_{\varepsilon_{i}}^{2}(t)$ in equation (9) represents the average idiosyncratic variance of stocks within the universe under consideration. The second term $-\sum_{i=1}^{N_{t}} w_{i t}^{2} \sigma_{\varepsilon_{i}}^{2}(t)$ is the negative bias that was also present even in the presence of homogeneous beta assumptions. If we focus on the equally-weighted scheme, the sum of these two terms is equal to $\frac{1}{N_{t}} \sum_{i=1}^{N_{t}} \sigma_{\varepsilon_{i}}^{2}(t)\left(1-\frac{1}{N_{t}}\right)$ so that the bias disappears in the limit of an increasingly large number of stocks. The third term $E\left[F_{t}^{2} C S V_{t}^{\beta}\right]$ in equation (9) represents, on the other hand, an additional (positive) bias for the CSV as an estimator of average idiosyncratic 
variance, which is introduced by the cross-sectional dispersion in betas, and which does not disappear in the limit of an infinitely large number of stocks.

In section A, we use this explicit expression to directly measure the beta dispersion bias using the CAPM and the Fama and French three-factor model as benchmark factor models. An extensive analysis of the CSV in the empirical section suggests that the homogeneous beta assumption does not represent a material problem for the CSV as an estimator of idiosyncratic variance as implied by standard asset pricing models (i.e. CAPM and FamaFrench).

\section{E Competing Measures of Idiosyncratic Risk}

In this section, we describe measures that have been used in the literature and which will be used for comparison purposes in subsequent sections of the paper. The standard approach consists of considering idiosyncratic variance either relative to the CAPM and or to the Fama-French (FF) model (Fama and French (1993)):

$$
r_{i t}=b_{0 i t}+b_{1 i t} X M K T_{t}+b_{2 i t} S M B_{t}+b_{3 i t} H M L_{t}+\varepsilon_{i t}^{F F}
$$

where $r_{i t}$ denotes the excess return at time $t$ of stock $i, X M K T$ is the excess return on the market portfolio, $S M B$ is the size factor and $H M L$ is the value factor. The idiosyncratic variance for asset $i$ is the variance of the residuals of the regression, that is $\sigma^{2}\left(\varepsilon_{i t}^{F F}\right)$. To

obtain an estimate for average idiosyncratic variance, Bekaert et al. (forthcoming) use a market capitalization weighting:

$$
F F_{t}^{C W}=\sum_{i=1}^{N_{t}} w_{i t} \sigma^{2}\left(\varepsilon_{i t}^{F F}\right)
$$

For comparison purposes we also look at the equally-weighted average of FF idiosyncratic variance in what follows.

An alternative approach to average (mostly) idiosyncratic risk estimation has been sug- 
gested by Goyal and Santa-Clara (2003), with a measure given by:

$$
G S_{t}^{E W}=\frac{1}{N_{t}} \sum_{i=1}^{N_{t}}\left[\sum_{d=1}^{D_{t}} r_{i d}^{2}+2 \sum_{d=2}^{D_{t}} r_{i d} r_{i d-1}\right]
$$

where $r_{i d}$ is the return on stock $i$ in day $d$ and $D_{t}$ is the number of trading days in month $t^{9}$.

More recently, Bali, Cakici, and Levy (2008) proposed a model-independent measure of aggregate idiosyncratic risk which does not require estimation of market betas nor correlations and which is based on the concept of gain from portfolio diversification:

$$
\sigma_{\varepsilon, t}^{2}=\left(\sum_{i=1}^{n} w_{i, t} \sigma_{i, t}\right)^{2}-\operatorname{Var}\left(R_{m, t}\right),
$$

where $\left(\sum_{i=1}^{n} w_{i, t} \sigma_{i, t}\right)^{2}$ is the variance of the non-diversified portfolio and $\operatorname{Var}\left(R_{m, t}\right)$ is the variance of the fully diversified portfolio, that is the market variance ${ }^{10}$.

\section{Empirical Implementation}

In order to perform an empirical analysis of our measure for idiosyncratic risk, we collect daily US stock returns (common equity shares only) and their market capitalization from the CRSP data base. Our longest sample runs from July 1963 to December 2006. We also extract the FF factors and the one-month Treasury bill from Kenneth French web-site data library for the same sample period. Each month, we drop stocks with missing returns and with non-positive market capitalization at the beginning of the month. The number of firms

\footnotetext{
${ }^{9}$ As in Goyal and Santa-Clara (2003), when the second term makes the estimate negative, it is ignored.
} This measure has been originally used in French, Schwert, and Stambaugh (1987).

${ }^{10}$ Campbell et al. (2001) propose an alternative measure of average idiosyncratic variance. They assume that all betas are equal to one and subtract industry returns in addition to market returns to control for risk. We do not include this measure in our comparison because Bekaert et al. (forthcoming) have shown that it is very closely related to the measure obtained from standard asset pricing models. 
varies between 377 and 7293, and remains greater than one thousand $75 \%$ of the time. The maximum number of stocks is reached during the dot.com bubble. Then, we estimate every month the cap-weighted ${ }^{11}$ and equal-weighted average idiosyncratic variance relative to the FF, CAPM, GS and Bali measures in equations (11), (12) and (13) respectively. We also estimate on a daily basis the equal and cap-weighted versions of the $C S V$ as in equations (4) and (5). In order to construct the monthly series for our cross-sectional measures, we estimate the average of the daily series at the end of each month. We annualize all figures in order to compare daily and monthly measures. Following Bekaert et al. (forthcoming), we fit a regime-switching model to the monthly and daily series in order to further compare the different measures. Last, we look at the relation between the CSV measures of idiosyncratic variance and selected economic and financial variables.

\section{A Measuring the CSV Bias}

As illustrated in Proposition 4 and discussed in Appendix C, the presence of non-homogeneous betas introduces a positive bias on the CSV as an estimator for average idiosyncratic variance, which is given by the last term in equation (9). We now measure the impact of this bias with respect to the CAPM as a benchmark model.

First, we compute the bias $E\left[F_{t}^{2} C S V_{t}^{\beta}\right]$ for every month in the sample using beta estimates for each stock with both the equal-weighted and the cap-weighted market returns. To gauge its importance, we divide it by the average idiosyncratic variance, also measured with respect to the $\mathrm{CAPM}^{12}$.

Table 1 presents a summary of the distribution of the time series of cross-sectional dispersion of betas, its product with the squared return of the market portfolio (hence the bias itself) and the proportion of this bias with respect to the average idiosyncratic variance at the end of every month. Although the cross-sectional dispersion of betas is sizable, once it is multiplied by the squared return of the market portfolio, the size of the bias remains

\footnotetext{
${ }^{11}$ We use previous period market capitalization and assume it is constant within the month.

${ }^{12}$ This is measured as in equation (11) with just the market returns with both weighting schemes.
} 
relatively small. The median of the distribution of $\frac{F_{t}^{2} C S V_{t}^{\beta}}{\sigma_{\varepsilon_{t}}^{2}}$ is $0.348 \%$ for the equal-weighted scheme and $0.351 \%$ for the cap-weighted measure, computed over the whole sample (July 1963 to December 2006). The 97.5 quantiles are $3.24 \%$ and $3.47 \%$ respectively.

On the other hand, the formal discussion about the properties of the CSV as a measure of idiosyncratic variance on section D also uncovered the fact that another bias (but negative in sign) coming from the CSV weighting scheme concentration is also introduced.

Using the explicit expression for this bias provided in Proposition 4 we estimate the proportion of the size of this weights-concentration bias with respect to the average idiosyncratic variances implied by the $\mathrm{CAPM}^{13}$. In the last line of the upper and lower panels of Table 1 we report quantiles of the distribution of this bias for both weighting schemes. The corresponding medians are $0.030 \%$ and $0.426 \%$ for the EW and CW schemes respectively. Since the bias is of opposite sign to the beta cross-sectional dispersion bias, we need to assess the resulting overall bias.

We measure the total bias as the intercept of a regression of the CSV on the average idiosyncratic variance estimated with respect to the CAPM or the Fama-French three-factor model:

$$
C S V_{t}^{w_{t}}=\text { bias }+\psi \sigma_{\text {model }}^{2}\left(w_{t}\right)+\zeta_{t},
$$

where $w_{t}$ refers to the weighting scheme (equal-weight or market-cap) and model stands for either the CAPM or the Fama-French three-factor model.

Table 2 reports summary statistics for regression (14). The bias of the CSV measured with respect to standard asset pricing models is small in magnitude for both weighting schemes (in the order of $10^{-5}$ ). While it remains statistically significant, we can safely consider that the impact of the bias remains immaterial for any practical purposes. Another interesting finding is the sign of the bias. For the equal-weighted quantities, the sign of the

\footnotetext{
${ }^{13}$ As noted earlier, it would be straightforward to remove the impact of this bias by dividing the CSV measure by the factor $\left(1-\sum_{i=1}^{N_{t}} w_{i t}^{2}\right)$, equal to $\left(1-\frac{1}{N_{t}}\right)$ in the EW case.
} 
bias is positive, while it is negative for the cap-weighted ones. Therefore, the beta bias dominates the weighting bias for equal-weighted averages in both models. This is consistent with the prediction made by the theoretical analysis regarding the relative impact of the weighting-bias for different weighting schemes. Regarding the model, the bias is larger when the idiosyncratic variance is measured with respect to the Fama-French model instead of the CAPM for both weighting schemes, as expected, but its magnitude remains negligible.

\section{B Comparison with Other Measures}

In this section we compare the CSV measure to the aforementioned measures of idiosyncratic risk (i.e., FF-based, CAPM-based, GS and Bali). To obtain the factor-based measures, we need to re-estimate the relevant factor model using a rolling window of one-month worth of daily data to allow for time-variation in beta estimates (or total-variance variation for the GS). In Table 3, we report summary statistics for the monthly time series of annualized idiosyncratic variances based on 516 observations from January 1964 to December $2006^{14}$.

On the monthly series, the annualized means of the equally-weighted CSV, FF-based and CAPM-based measures are 38.4\%, 38.3\% and 38.7\%, respectively, while the EW GS and Bali variances are $34.2 \%$ and $23.6 \%$. The standard deviations are $8.5 \%, 8.6 \%, 8.7 \%$ for the CSV, FF-based and CAPM-based measures and 7.0\% and $4.7 \%$ for the GS and Bali measures. For the cap-weighted version, the CSV, FF and CAPM idiosyncratic variance measures have an annualized mean of 8.5\%, 7.6\%, 8.0\%, respectively and the GS and Bali measure means are $11.2 \%$ and $6.5 \%$. The standard deviations are also closer for the CSV, FF, CAPM and Bali measures than for GS. Although GS argue that their measure fundamentally constitutes a measure of idiosyncratic risk, it is strictly speaking an average of total stock variance.

The cross-correlation matrix reported in Table 3 provides further evidence on the closeness of the CSV to the other model-based measures. Correlations are high between $C S V^{E W}$

\footnotetext{
${ }^{14}$ In this section of the paper, we start the sample period in January 1964 to allow for direct comparison with Bekaert et al. (forthcoming). In the predictability section, we instead start the sample in July 1963.
} 
and $C A P M^{E W}(99.93 \%), F F^{E W}(99.75 \%)$ and Bali $^{E W}(97.75 \%)$, as well as between $C S V^{C W}$ and $C A P M^{C W}(99.48 \%), F F^{C W}$ (98.56\%) and Bali ${ }^{C W}$ (99.36\%). The high correlations between the CAPM and the FF measures $(99.88 \%$ and $99.18 \%$ for EW and CW respectively) also indicate that adding factors does not drastically affect the estimation of idiosyncratic variance. Correlations between the GS measures and the other measures are always smaller but remain close to $90 \%$ when considering the same weighting scheme. Correlations between measures for different weighting schemes are much lower, irrespective of the estimation method, indicating that the choice over the weighting scheme is fundamentally important for estimating idiosyncratic variance, as stressed in our theoretical analysis in section II.

Table 4 provides mean and standard-deviation estimates for the daily average idiosyncratic variance measures. The mean of the EW CSV is $38.4 \%$, practically equal to the mean of EW idiosyncratic variance based on the $\mathrm{FF}$ model ${ }^{15}$. For the cap-weighted measures, the CSV has a slightly higher mean than the FF-based one. For the CSV daily series, the standard deviation is higher than for the FF-based measure for both weighting schemes. This is due to the different nature of the two series. The CSV only includes information from the cross-section of realized returns, while the FF idiosyncratic variance is a persistent, overlapping, rolling-window estimate.

The lower panel of Table 4 presents cross-correlations for the daily series of idiosyncratic variance measures. Although the coefficients are smaller than for the monthly series, the relationship remains strong provided the comparison is done for the same weighting scheme: 82.6\% and $73.9 \%$ for EW and CW measures respectively. The difference with the monthly series correlations may again be explained by the presence of the smoothed estimation procedure inherent to the FF-based measure.

\footnotetext{
${ }^{15} \mathrm{It}$ is estimated based on a rolling-window of one month.
} 


\section{Cross-sectional Volatility - Regimes and Relation with Eco- nomic and Financial Variables}

Bekaert et al. (forthcoming) fit a Markov regime-switching model with a first-order autocorrelation structure for the monthly series of idiosyncratic variance based on the FF model. We estimate this model with our CSV measure both at the monthly and daily frequencies. In this model, two regimes are indexed by a discrete state variable, $s_{t}$, which follows a Markov-chain process with constant transition probabilities. Let the current regime be indexed by $i$ and the past regime by $j$ and $x_{t}$ be the original idiosyncratic variance, which follows an $\mathrm{AR}(1)$ model:

$$
x_{t}-\mu_{i}=\phi\left(x_{t-1}-\mu_{j}\right)+\sigma_{i} e_{t}, i, j \in\{1,2\}
$$

The transition probabilities are denoted by $p=P\left[s_{t}=1 \mid s_{t-1}=1\right]$ and $q=P\left[s_{t}=\right.$ $\left.\left.2 \mid s_{t-1}=2\right]\right)$. The model involves a total of 7 parameters, $\left\{\mu_{1}, \mu_{2}, \sigma_{1}, \sigma_{2}, \phi, p, q\right\}$.

We report the estimation results in Panel A of Table 5 for the equally-weighted CSV, monthly and daily, and for the FF-based measure monthly. We observe that the monthly estimates obtained for the CSV and the FF-based measures are very similar. For both measures, the low-mean, low-variance regime displays a higher probability of remaining in the same state ${ }^{16}$. We estimated the same model for the daily CSV series. The estimated values of the mean parameters $\mu_{1}$ and $\mu_{2}$ are quite close to the values obtained with the monthly series. This result suggests that we capture the same process at different frequencies $^{17}$. The resulting filtered probabilities suggest that the CSV measure is counter-cyclical, the dispersion of returns being high and quite variable when economic growth subsides.

\footnotetext{
${ }^{16}$ Similar results for the cap-weighted CSV are not included for space considerations.

${ }^{17}$ This is of course not the case for the daily FF-based measure, since it is an overlapping measure of idiosyncratic variance. This results in a high degree of persistence, with an autocorrelation parameter very close to one, and similar means in both regimes.
} 
Recently, Bansal and Yaron (2004) have revived consumption-based asset pricing models by showing that two sources of long-run risk - expected consumption growth and consumption volatility as a measure of economic uncertainty — determine asset returns. Further, Tédongap (2010) provides strong evidence that consumption volatility risk explains a high percentage of the cross-sectional dispersion in average stock returns for the usual set of size and book-to-market portfolios. In tests of the intertemporal CAPM or the conditional CAPM, the cross-section of expected returns is linked to other economic or financial variables such as the term spread, default spread, implied or realized measures of aggregate returns variance, and many others. We relate our CSV measure to some of these variables.

Our first economic variable is consumption-growth volatility as a measure of economic uncertainty. Following Bansal and Yaron (2004) and Tédongap (2010), we filter consumptiongrowth volatility with a GARCH model. For consumption, we used FRED's personal consumption expenditures of non-durables and services monthly series, divided by the consumer price index and the population values to obtain a per-capita real consumption series. We then compute its growth rate from July 1963 to $2006^{18}$. The second economic variable we consider is inflation volatility, which we filter also with a GARCH process ${ }^{19}$. For the financial variables we use Welch and Goyal (2008)'s data for corporate bond yields on BAA and AAA-rated bonds, long-term government bond yield and 3-month T-bill rate to estimate the credit spread and term spread (as the difference between the first and the second rate

\footnotetext{
18 The series IDs at the FRED's webpage are, PCEND and PCES for "Personal Consumption Expenditures: Nondurable Goods" and "Personal Consumption Expenditures: Services", CPIAUCNS for "Consumer Price Index for All Urban Consumers: All Items" and POP for "Total Population: All Ages including Armed Forces Overseas". Bansal and Yaron (2004) used the Bureau of Economic Analysis data available at www.bea.gov/national/consumer_spending.htm on real per-capita annual consumption growth of nondurables and services for the period 1929 to 1998. The series is longer but is available only at annual and quarterly frequencies.

${ }^{19}$ For space considerations, we do not report parameter estimates for the two $\operatorname{AR}(1)$-Garch $(1,1)$ we estimate. They are available upon request from the authors.
} 
in both cases $)^{20}$. In Panel B of Table 5 we report the results of univariate regressions of the equally-weighted measure of cross-sectional variance on the five economic and financial variables during the 1990-2006 period. We also explore some potential asymmetries by computing the $C S V^{E W}$ for the positive and negative returns.

We observe that the $R^{2}$ for consumption growth volatility is close to 16 per cent. In Figure 1 we plot the two series over the same sampling period. While the CSV series is much noisier than consumption-growth volatility, the coincident movements between the two series are quite remarkable. This suggests the presence of a common factor (aggregate economic uncertainty) that affects the idiosyncratic variance of each security. Aggregating over all securities will make the CSV a function of economic uncertainty ${ }^{21}$.

The next most highly negatively correlated variable is inflation volatility with a $R^{2}$ of 13 per cent. Since 1998, inflation volatility has been on an upward trend, while the crosssectional variance of returns has been sharply declining. In presence of higher inflation uncertainty, investors will allocate more to stocks relative to bonds in their portfolios, generating a general increase in stock returns that reduces their cross-sectional variance. The T-bill rate is also relatively highly correlated with $C S V^{E W}$ with a $R^{2}$ close to 9 per cent. In the type of equilibrium models we have referred to, the risk-free rate, proxied here by the T-bill, will be a function of consumption growth volatility, hence its positive relation with the cross-sectional variance.

For the financial variables (credit spread and term spread), the signs obtained are intuitive. Credit risk affects differently individual firm returns and therefore tends to increase CSV, while a pervasive term spread risk will reduce dispersion by being common to many securities due to a move of investors away from bonds into the stock market. However, the relations are not statistically significant, although the relation improves for the CSV com-

\footnotetext{
${ }^{20}$ Data available at Amit Goyal's webpage: http://www.bus.emory.edu/AGoyal/Research.html

${ }^{21}$ In intertemporal asset pricing models of Bansal and Yaron (2004) and Bollerslev, Tauchen, and Zhou (2009), economic uncertainty is a priced risk factor that affects returns, therefore providing a fundamental rationale for the observed correlation between CSV and consumption growth volatility.
} 
puted with negative returns. Therefore, it is in bear periods that these risk variables seem to affect most the dispersion of returns. This asymmetry between positive and negative returns is also present for consumption volatility.

\section{New Evidence on the Predictability of the Market Return}

There is an ongoing debate on the predictive power of average idiosyncratic variance for average (or aggregate) stock market returns. Goyal and Santa-Clara (2003) find a significantly positive relationship between the equal-weighted average idiosyncratic stock variance and the cap-weighted portfolio returns for the period 1963:07 to 1999:12. They find that their measure of average idiosyncratic variance has a significant relationship with next month return on the cap-weighted portfolio. The regression in GS is as follows:

$$
r_{t+1}^{C W}=\alpha+\beta \nu_{t}^{E W}+\varepsilon_{t+1}
$$

where $\nu_{t}^{E W}$ corresponds to $G S_{t}^{E W}$. In a subsequent analysis, Bali et al. (2005) argue that this relationship disappeared for the extended sample 1963:07 to 2001:12, and attribute the relationship observed in GS to high-tech-bubble-type stocks (i.e., stocks traded on the NASDAQ) and a liquidity premium. In a similar way, Wei and Zhang (2005) find that the significance of the relationship found by GS disappeared for their sample 1963:07 to 2002:12 and argue that the presumably temporary result of GS was driven mainly by the data in the 1990s. Wei and Zhang (2005) criticize the fact that GS looked at the relationship between an equally-weighted average stock variance and the return on a cap-weighted average stock return, as opposed to an equally-weighted portfolio return. Moreover, both Bali et al. (2005) and Wei and Zhang (2005) find no significant relationship between the cap-weighted measures and the cap-weighted portfolio return in all three sample periods (ending in 1999, 2001 and 2002, respectively). 


\section{A Monthly Evidence}

In this section we confirm existing results and extend them in a number of dimensions, including a longer sample period. The first panel in Table 6 presents the predictability regression of the cap-weighted return by equally-weighted variance measures as in Goyal and Santa-Clara (2003) and Bali et al. (2005) for their sample periods, as well as for the extended sample up to 2006:12. The regression is as in equation (16), where $\nu_{t}^{E W}$ corresponds to the EW CAPM-based measure and the $\mathrm{CSV}^{22}$. For comparison purposes we start the sample period in this section in 1963:07, as in Goyal and Santa-Clara (2003), Bali et al. (2005) and Wei and Zhang (2005).

For the monthly series, we confirm that there is a significant positive relationship in the first sample, and also that it weakens for the subsequent extended samples ${ }^{23}$. The Newey and West (1987) autocorrelation corrected t-stat for 12 lags of the $\beta$ coefficient of both CSV and the CAPM-based measures goes from 3.54 for the first sample period down to 0.96 for the largest sample. Consequently, the adjusted $R^{2}$ goes from $1.3 \%$ down to $0.04 \%$. Therefore the findings of Bali et al. (2005) and Wei and Zhang (2005) are also present in the extended sample. In Section $\mathrm{C}$ we propose a possible explanation for this result.

In the second panel of Table 6 we present the results of the regression between the equallyweighted average return and the lagged equally-weighted idiosyncratic variance measure, as given by:

$$
r_{t+1}^{E W}=\alpha+\beta \nu_{t}^{E W}+\varepsilon_{t+1}
$$

where $\nu_{t}^{E W}$ is taken as the CAPM-based average idiosyncratic variance or as the CSV measure. In contrast with the former regression, the relationship is found to be significantly

\footnotetext{
${ }^{22}$ As explained before, the monthly CSV is the average of its daily values during the month.

${ }^{23}$ We found a similar result using the GS measure of equally-weighed average variance. We do not present these regression results for the sake of brevity given that they produce similar findings, which have also been confirmed in Bali et al. (2005) and Wei and Zhang (2005).
} 
positive for the three sample periods and for both measures ${ }^{24}$.

In the third panel of Table 6 we present the results for the three sample periods of the one-month-ahead predictive regression of the cap-weighted market portfolio using the cap-weighted idiosyncratic variance return as a predictor. In this case, the beta of the idiosyncratic variance is not significant for all three sample periods. This result confirms the findings of Bali et al. (2005) and Wei and Zhang (2005) for the extended sample.

\section{B New Predictability Evidence at Daily Frequency}

Prevailing measures used in the literature require a sample of past data to estimate additional parameters, constraining existing evidence to the monthly estimations. Fu (2009) finds that high idiosyncratic volatilities of individual stocks are contemporaneous with high returns, which tend to reverse in the following month. Huang, Liu, Rhee, and Zhang (2010) find that the negative relationship between idiosyncratic variance and expected returns at the stock level uncovered in Ang et al. (2006) and Ang, Hodrick, Xing, and Zhang (2009) becomes positive after controlling for the return reversals. Looking at the predictability relation at a higher frequency than the month may help sort out these effects. Taking advantage of the instantaneous nature of the CSV, we run the same predictability regression (17) on the one-day-ahead portfolio return using the average idiosyncratic variance.

The upper panel of Table 7 shows that at a daily basis, this relationship is much stronger, with (Newey-West corrected) t-stats of coefficients for the average idiosyncratic variance across the three samples ranging between 4 and 4.7 .

\footnotetext{
${ }^{24}$ Wei and Zhang (2005) find a significantly positive relation between the equal-weighted GS measure and the equal-weighted market return for the initial sample. They also test the robustness of the relation by using an equally-weighted cross-sectional variance of monthly returns. They found a significantly positive coefficient for predicting the equal-weighted portfolio return mainly for the long samples starting in 1928 but not for the sample going from 1963 to 2002. Note that our cross-sectional measures differ. Ours is an average of the daily cross-sectional variances over the month. Theirs is the cross-sectional variance of the returns computed over the month.
} 
In the lower panel of Table 7 we report the results for the one-day-ahead predictive regression on the cap-weighted pairs (CSV and market return). The relation is positive and significant for all three samples, but the t-stat on the cap-weighted idiosyncratic variance coefficient deteriorates as we increase the period, from about 5.91 in the first sample down to 1.97 for the longest sample.

\section{Interpretation of Predictability Results}

The relationship between the equal-weighted average idiosyncratic variance and the capweighted market index observed up to the end of the 1990 can be explained by the heterogeneous and transitory nature of the omitted sources of risk captured by idiosyncratic risk and its relation with the inflated valuation of several NASDAQ companies during that $\operatorname{period}^{25}$.

Some intuition behind the far more robust relationship between the equally-weighted average idiosyncratic variance and the equally-weighted portfolio comes precisely from the logic of standard asset pricing theory. As discussed in Section V, several theories can be invoked to link average idiosyncratic risk to average returns, due to the heterogeneous sources that may compose idiosyncratic risk. According to the CAPM, only systematic risk should explain future returns. However, if during a certain period of time there exists anomalies of any kind (priced omitted risk factors) that, presumably, are not proportionally reflected in the current market capitalization of the companies carrying these factors, then the omitted sources of risk are more likely to explain the returns of an equally-weighted

\footnotetext{
${ }^{25}$ In that sense, we agree with Wei and Zhang (2005) and Bali et al. (2005). The strongest omitted factor in that period (call it the irrational.com factor), partially captured by the equally weighted idiosyncratic variance, started to be increasingly represented in the market-cap index, due to the suddenly-higher market capitalization of precisely the group of companies carrying this temporarily strong omitted factor. The subsequent burst of the bubble explains the strong attenuation of the relationship between the average idiosyncratic variance and the market-cap portfolio, since most stocks carrying this irrational.com factor lost value and their weight fell in the market-capitalization index.
} 
portfolio than the returns of a value-weighted portfolio.

Along these lines, Pontiff (2006) argues that idiosyncratic risk is the largest holding cost borne by rational arbitrageurs in their pursuit of mispricing opportunities. This theory implies that the current level of idiosyncratic risk should predict returns since it should measure the amount of current mispricing opportunities present in the market. All things being equal, large-cap stocks are less likely to present misspricing and hence the predictability implied by this theory would be more likely to be present on the equal-weighted index return rather than the cap-weighted index return, as we observed in predictive regressions at daily and monthly horizons ${ }^{26}$. Moreover, assuming that mispricing opportunities tend to disappear in the long run, it appears more likely to observe this relationship between idiosyncratic variance and returns over very short horizons. This is consistent with our results. The sign of the relationship is not predicted by Pontiff's theory in general, because it depends on whether the average (equal or cap-weighted) portfolio is over- or under-priced (it predicts a positive sign for underpriced stocks and a negative sign for overpriced stocks).

\section{Robustness of Predictability}

In this section, we test further the predictability documented in the former section. First, we control for some usual macroeconomic and financial predictors. Next, we include other measures of variance in the predictability regression. Finally we check for the presence of asymmetry in the relationship between idiosyncratic variance and future average returns.

\section{D.1 Inclusion of Macroeconomic and Financial Predictors}

Several authors (see in particular (Bali et al. (2005) and Goyal and Santa-Clara (2003)) have suggested to estimate the risk-return trade-off predictability regression with various control

\footnotetext{
${ }^{26}$ It is well known that large cap stocks are more liquid than small-cap stocks, which implies a higher number of people trading them and usually a higher number of analysts looking at them. Together with less constraints to short-selling, we expect a higher price efficiency for large cap stocks.
} 
variables to account for potential changes in the investment opportunity $\operatorname{set}^{27}$. We consider four macroeconomic and financial variables: the aggregate dividend yield (DIV), the term spread (TERM), the default or credit spread (DEF) and the relative T-bill rate (RREL). Over the longest sample period we have considered, July 1963 to December 2006, only the variables DIV, TERM and RREL are available at both daily and monthly frequencies. For this long sample, the default or credit spread is only available at the monthly frequency. At the daily frequency, the latter series starts only in December 1996.

Table 8 reports the daily and monthly regression estimates for predicting the returns of the equally-weighted $\left(r^{E W}\right)$ and cap-weighted $\left(r^{C W}\right)$ indexes. At the daily frequency, the predictive power of CSV remains unaffected by the presence of the macroeconomic and financial variables. The coefficients are close to the values found in the univariate regression. Of the three added variables, only the relative T-bill rate appears as a strongly significant predictor. This is true for both $r^{E W}$ and $r^{C W 28}$. At the monthly frequency, the predicting capacity of $C S V^{E W}$ for $r^{E W}$ remains after controlling for the macroeconomic variables, while $C S V^{C W}$ is still a non-significant predictor of $r^{C W}$. These results are consistent with Bali et al. (2005) for a shorter sample ending in December 1999.

\section{D.2 Inclusion of Return Variance}

We now include the variance of the market portfolio in the predictability regression. For the monthly estimations of $\operatorname{Var}\left(r_{t}^{E W}\right)$ we use the realized sample variance over the month computed from daily returns. For the daily estimations we fitted an $\operatorname{AR}(1)$-EGARCH$(1,1)$ model on the overall sample ${ }^{29}$. In the first two panels of Table 9, we report regression results at the monthly and daily frequency. In the univariate regression, the variance of

\footnotetext{
${ }^{27}$ This is to capture the intertemporal hedging demand components in an ICAPM framework.

${ }^{28}$ On the reduced sample from December 1996, the default spread does not appear significant. The only significant variable is the dividend yield in the regression forecasting $r^{C W}$.

${ }^{29}$ Using the overall sample to estimate the parameters would only give the portfolio variance an advantage to predict future returns. However, we find that even when using such forward-looking estimates for $\operatorname{Var}\left(r_{t}^{E W}\right)$, the significance of the CSV remains strong.
} 
the equally-weighted portfolio returns does not appear to be significant in explaining the average future returns at the monthly and daily frequencies.

In the bivariate regression, the coefficient of $\operatorname{Var}\left(r_{t}^{E W}\right), \vartheta$, is negative and non-significant at the monthly frequency. At the daily frequency, the coefficient $\vartheta$ is still negative and (marginally) significant. For both monthly and daily frequencies, the significance of the $C S V$ coefficient improves slightly after the inclusion of the equally-weighted portfolio variance.

In the two bottom panels of Table 9, we report the regression results at monthly and daily frequencies using the cap-weighted index and CSV equivalents. The relationship at the daily horizon becomes non-significant after the inclusion of the realized variance of the market cap-weighted index. At the monthly horizon, the relationship remains non-significant.

Other measures of variance have been used in trying to link market returns to a measure of market risk. Option-implied variance $\left(V I X^{2}\right)$ has been used as a forward-looking measure of market variance in addition to realized variance (the sum of squared returns at higher frequency than the targeted frequency for the measure of variance) $)^{30}$. Results with these measures are similar to the ones we just reported ${ }^{31}$.

\section{D.3 Asymmetry in the Cross-Sectional Distribution of Returns}

We now test for an asymmetry in the relationship between idiosyncratic variance and future average returns. First, the cross-sectional variance is split in two and is computed for returns above or below the mean. Second, we compute a robust measure of the cross-sectional skewness.

This asymmetry may be the result of the leverage effect put forward by Black (1976) since we are considering individual firms in the cross section. Consumption volatility risk may also affect differently small and large firms or value and growth firms. Therefore, we

\footnotetext{
${ }^{30}$ For example, for the monthly variance, one will sum the daily squared returns, while for the daily variance, it is customary to use five-minute or one-minute squared returns.

${ }^{31}$ These results are available upon request from the authors.
} 
test $i$ ) whether the predictability power is the same for the CSV of returns to the left and right of the center of the returns' distribution, $i i$ ) whether the relationship is driven by one of the sides and $i i i$ ) whether the sign of the coefficient is the same on both sides. Therefore, we define $C S V_{t}^{+}$as the cross-sectional variance of the returns to the right of the crosssectional distribution (that is the cross-sectional distribution that includes all stocks such that $r_{i t}>r_{t}^{E W}$ ) and conversely define $C S V_{t}^{-}$as the cross-sectional variance of the returns to the left of the cross-sectional distribution (that is the cross-sectional distribution that includes all stocks such that $\left.r_{i t}<r_{t}^{E W}\right)$. Then we run the following regression:

$$
r_{t+1}^{E W}=\alpha+\beta^{+} C S V_{t}^{+}+\beta^{-} C S V_{t}^{-}+\epsilon_{t+1}
$$

Table 10 presents the results of regression (18) for daily and monthly estimates. First, we observe that splitting the CSV into right and left sides of the cross-sectional distribution make the adjusted $R^{2}$ of the predictive regression increase from $0.8 \%$ to $1.11 \%$ in monthly data and from $0.6 \%$ to $1.55 \%$ in daily data. Second, there is an asymmetric relationship between the CSV of the returns to the right and left of the cross-sectional distribution and the expected market return: the coefficient of the $C S V_{t}^{+}$is positive while the one of $C S V_{t}^{-}$ is negative in both daily and monthly regressions, and, for the daily equally-weighted CSV, the magnitude of the coefficients differs significantly. However, for the monthly regressions, the coefficients are mostly non-significant.

The summary statistics of the predictive regression on the cap-weighted index using the equivalent cap-weighted CSV measures, displayed in the right-hand side upper panel of Table 10, are qualitatively similar to the results on the equal-weighted measures.

These findings suggest that a measure of asymmetry of the cross-sectional distribution would be relevant in the context of exploring the relationship between market expected returns and aggregate idiosyncratic risk. Another key advantage of the cross-sectional nature of the CSV measure is that it can be easily extended to higher-order moments. Therefore 
we consider below the skewness of the cross-sectional distribution of returns and assess its predictive power for future returns. To the best of our knowledge, this additional factor, which appears as a natural extension of the CSV for measuring idiosyncratic risk ${ }^{32}$, is new in this context ${ }^{33}$. We follow Kim and White (2004) and use a quantile-based estimate (see Bowley (1920)), generalized by Hinkley (1975), as a robust measure of skewness for the cross-sectional distribution of returns ${ }^{34}$ :

$$
R C S=\frac{F^{-1}\left(1-\alpha_{1}\right)+F^{-1}\left(\alpha_{1}\right)-2 Q_{2}}{F^{-1}\left(1-\alpha_{1}\right)+F^{-1}(\alpha 1)}
$$

for any $\alpha_{1}$ between 0 and 0.5 and $Q_{2}=F^{-1}(0.5)$. The Bowley coefficient of skewness is a special case of Hinkley's coefficient when $\alpha_{1}=0.25$ and satisfies the Groeneveld and Meeden (1984)'s properties for reasonable skewness coefficients. It has upper and lower bounds $\{-1,1\}$.

In the two lower panels of Table 10 we report the results of a univariate regression of daily and monthly returns on the equal-weighted and cap-weighted market indexes on the robust measure of cross-sectional skewness. The coefficients of skewness in the daily regressions are highly significant. The $R^{2}$ for the equal-weighted market returns is above $5 \%$ at the daily level. At the monthly frequency, skewness is a significant predictor only for the equallyweighted index. The sign of the coefficient of skewness is positive, which means that a shock resulting in an increase of the positive skewness of the cross-sectional distribution of returns

\footnotetext{
${ }^{32}$ We show formally in an appendix available upon request from the authors that there is a link between idiosyncratic skewness and the skewness of the cross-sectional distribution of returns.

${ }^{33}$ At the stock level, Kapadia (2009) uses cross-sectional skewness to explain the puzzling finding in Ang et al. (2006) that stocks with high idiosyncratic volatility have low subsequent returns, while Bali, Cakici, and Whitelaw (2011) examine the role of extreme positive returns in the cross-sectional pricing of stocks.

${ }^{34}$ The usual non-robust skewness measure of the cross-section of returns is highly noisy compared to the proposed robust measure, especially at the daily frequency.
} 
will translate in higher expected returns next period $^{35}$. We can invoke the same mispricing arguments as in section C. Our findings are also consistent with the differentiated impact of investor sentiment on the prices of individual securities. Baker and Wurgler (2006) run predictability regressions for equal-weighted and cap-weighted market returns using proxies for investor sentiment at the monthly frequency. They find that when sentiment is low small stocks earn particularly high subsequent returns. When sentiment is high there is no size effect. This would explain both the positive sign for skewness and the fact that capitalization weighting obscures the pattern.

In Table 11, we report the results of predictive regressions at the daily and monthly frequencies where we add the robust measure of the cross-sectional skewness to the CSV measures and macroeconomic variables included in Table 8. The first observation is that the magnitude and the significance of the CSV measures are very close to the values reported in Table 8. However, the striking fact is that skewness remains the major contributor to the predictability of returns since the $R^{2}$ increases significantly compared to the regressions including CSV and macroeconomic variables. At the daily frequency, the adjusted $R^{2}$ increases to close to $6 \%$ (from $1.4 \%$ ). At the monthly frequency, it goes up to almost $8 \%$ (from $5.7 \%$ ). This robustness check shows that the skewness effect goes beyond good and bad times defined by macroeconomic conditions.

\section{Is Average Idiosyncratic Risk Priced?}

Several theoretical papers predict a positive relation between idiosyncratic risk and expected returns. Levy (1978), Merton (1987) and Malkiel and Xu (2002) pricing models relate stock

\footnotetext{
${ }^{35}$ Several theoretical papers predict lower expected returns for stocks with idiosyncratic skewness; see among recent contributions Mitton and Vorkink (2007), Barberis and Huang (2008), and Brunnermeier, Gollier, and Parker (2007). This literature refers to the pricing of individual securities that exhibit skewness. Our result concerns the relation between aggregate idiosyncratic skewness and the expected aggregate return.
} 
returns to their beta with the market and their beta to market-wide measures of idiosyncratic risk. In these models, an important portion of investors' portfolios may differ from the market. Their holdings may be affected by corporate compensation policies, borrowing constraints, heterogeneous beliefs and include non-traded assets that add background risk to their traded portfolio decisions (e.g. human capital and private businesses). These theoretical predictions are also in line with Campbell et al. (2001)'s argument that investors holding a limited number of stocks hoping to approximate a well-diversified portfolio would end up being affected by changes in idiosyncratic volatility just as much as by changes in market volatility. More recently, Guo and Savickas (2008) argue that changes in average idiosyncratic volatility provide a proxy for changes in the investment opportunity set and that this proxy is closely related to the book-to-market factor ${ }^{36}$.

However, there is an ongoing empirical debate on the cross-sectional relation between idiosyncratic volatility and future stock returns. Ang et al. (2006) and Ang et al. (2009) find results that are opposite to these theories since stocks with high idiosyncratic volatility earn low average returns, but they cannot fully rationalize this result. Recently, Huang et al. (2010) have found that the negative sign in the relationship between idiosyncratic variance and expected returns at the stock level becomes positive after controlling for return reversals. Similarly, Fu (2009) documented that high idiosyncratic volatilities of individual stocks are contemporaneous with high returns, which tend to reverse in the following month. Bali et al. (2011) find that the negative effect of idiosyncratic volatility is driven by its close association with the maximum daily return in a month, proxying for demand for lottery-like stocks. Finally, Bali and Cakici (2008) show that there is no robust, significant relation between idiosyncratic volatility and the cross-section of expected returns. The relation is sensitive to portfolio construction methodology and data frequency.

\footnotetext{
${ }^{36}$ Alternative explanations of the relation between idiosyncratic risk and return are the firm's assets' call-option interpretation by Merton (1974) where equity is a function of total volatility as well as Barberis, Huang, and Santos (2001) prospect theory asset pricing model with loss aversion over (owned) individual stock's variance.
} 
In order to use the standard set of assets in the asset pricing literature, we extract daily returns data from Kenneth French data library on their 100 (10x10) and 25 (5x5) size/book-to-market portfolios for the period July 1963 to December 2006. Then we run every calendar month the following regression for each portfolio ${ }^{37}$ :

$$
r_{i t}=\alpha+\beta_{i, x m k t} X M K T_{t}+\beta_{i, s m b} S M B_{t}+\beta_{i, h m l} H M L_{t}+\beta_{i, c s v} C S V_{t}^{E W} .
$$

To estimate the factor loadings (the $\beta$ s) we use the past month or the past three months of daily data (to reduce measurement error) and run the following cross-sectional regression every month on the next month's excess returns and record the $\gamma$ coefficients:

$$
r_{i t+1}^{m}=\gamma_{0}+\gamma_{x m k t} \beta_{i, x m k t}(t)+\gamma_{s m b} \beta_{i, s m b}(t)+\gamma_{h m l} \beta_{i, h m l}(t)+\gamma_{c s v} \beta_{i, c s v}(t)
$$

We finally test whether the average $\gamma$ coefficients are statistically different from zero. In order to take into account possible serial correlation in the coefficients, we compute the t-statistic using Newey and West (1987) standard errors with 4 lags (same number of lags as in Ang et al. (2009)). We use four sets of assets: 100 (10x10) size/book-to-market equallyweighted portfolios and cap-weighted weighted portfolios, and 25 (5x5) size/book-to-market equally-weighted and cap-weighted portfolios. For each of them, we use the $C S V^{E W}$ as the fourth risk factor. In Table 12 we report the corresponding Fama-MacBeth regression results. The table displays the annualized coefficients and standard errors (multiplied by 12 from the original monthly values), as well as their corresponding autocorrelation-corrected t-stat and the average $R^{2}$. In Panel A, for the monthly beta estimates, the $\gamma$ coefficient for $C S V^{E W}$ is positive and significant when we use the 100 and 25 size/book-to-market FamaFrench equally-weighted portfolios. However, it is positive and not significant when we use

\footnotetext{
${ }^{37}$ As before, XMKT stands for excess market return, SMB and HML are the size and book to market Fama-French factors, also directly extracted from Kenneth French data library.
} 
the 25 market cap-weighted portfolios and marginally significant for the 100 market capweighted portfolios. The latter result is not entirely surprising considering that the crosssectional variation in returns is reduced through the market-capitalization adjustment. In Panel B, we report results for the three-month beta estimates to account for some potential measurement errors. The coefficient for the CSV loading is now significant for the 100 cap-weighted portfolios but not quite for the 25 .

\section{Conclusion}

We formally introduced a cross-sectional dispersion measure as a proxy for aggregate idiosyncratic risk that has the distinct advantage of being readily computable at any frequency, with no need to estimate other parameters. It is therefore a model-free measure of idiosyncratic risk. We extensively show how this measure is related to previous proxies of idiosyncratic variance, such as the measures proposed by Goyal and Santa-Clara (2003), Bali et al. (2008), and the ones based on the Fama and French (1993) and CAPM models, which have been previously shown to be very close to the Campbell et al. (2001) proxy as well. We confirm previous findings of Goyal and Santa-Clara (2003), Bali et al. (2005) and Wei and Zhang (2005) on the monthly predictability regressions for an extended sample period using our cross-sectional measure and more standard measures of idiosyncratic variance. We find that the results are robust across these measures. Thanks to the instantaneous nature of our measure, we are able to extend to daily data the evidence on the predictability power of idiosyncratic variance on the future market portfolio return. We provide a statistical argument to support the choice of an equally-weighted measure of average idiosyncratic variance as opposed to a market-cap weighted and explain why both empirically and theoretically such a measure should forecast better the equal-weighted market return. We also showed that this cross-sectional measure displays a sizable correlation with economic uncertainty, as measured by consumption growth volatility, and with several economic and financial variables. One additional advantage of the cross-sectional nature 
of our measure is that it generalizes to higher moments. We showed that the asymmetry of the cross-sectional distribution is a very good predictor for future returns. We leave for further research an exhaustive analysis of the properties of the skewness of cross-sectional return distribution as a measure of average idiosyncratic skewness as well as an empirical analysis of the CSV measure using international data. 


\section{References}

Allen, L., and T. Bali. "Cyclicality in Catastrophic and Operational Risk Measurements." Journal of Banking and Finance, 31 (2007), 1191-1235.

Ang, A.; R. Hodrick; Y. Xing; and X. Zhang. "The Cross-Section of Volatility and Expected Returns." The Journal of Finance, 61 (2006), 259-299.

Ang, A.; R. Hodrick; Y. Xing; and X. Zhang. "High Idiosyncratic Volatility and Low Returns: International and Further US Evidence." Journal of Financial Economics, 91 (2009), 1-23.

Baker, M., and J. Wurgler. "Investor Sentiment and the Cross-Section of Stock Returns." The Journal of Finance, 61 (2006), 1645-1680.

Bali, T., and N. Cakici. "Idiosyncratic Volatility and the Cross Section of Expected Returns." Journal of Financial and Quantitative Analysis, 43 (2008), 29-58.

Bali, T.; N. Cakici; and H. Levy. "A Model-Independnet Measure of Aggregate idiosyncratic Risk." Journal of Empirical Finance, 15 (2008), 878-896.

Bali, T.; N. Cakici; and R. Whitelaw. "Maxing Out: Stocks as Lotteries and the CrossSection of Expected Returns." Journal of Financial Economics, 99 (2011), 427-446.

Bali, T.; N. Cakici; X. Yan; and Z. Zhang. "Does Idiosyncratic Risk Really Matter?" The Journal of Finance, 60 (2005), 905-929.

Bansal, R., and A. Yaron. "Risks for The Long Run: A Potential Resolution of Asset Pricing Puzzles." The Journal of Finance, 59 (2004), 1481-1509.

Barberis, N., and M. Huang. "Stocks as Lotteries: The Implications of Probability Weighting for Security Prices." The American Economic Review, 98 (2008), 2066-2100. 
Barberis, N.; M. Huang; and T. Santos. "Prospect Theory and Asset Prices." Quarterly Journal of Economics, 116 (2001), 1-53.

Bekaert, G.; R. J. Hodrick; and X. Zhang. "Aggregate Idiosyncratic Volatility." Journal of Financial and Quantitative Analysis (forthcoming), forthcoming.

Black, F. "The Pricing of Commodity Contracts." Journal of Financial Economics, 3 (1976), $167-179$.

Bollerslev, T.; G. Tauchen; and H. Zhou. "Expected Stock Returns and Variance Risk Premia." The Review of Financial Studies, 22 (2009), 4463-4492.

Bowley, S. Elements of Statistics, Vol. 2, P.S. King and Son, London (1920).

Brandt, M.; A. Brav; J. Graham; and A. Kumar. "The Idiosyncratic Volatility Puzzle: Time Trend or Speculative Episodes." Review of Financial Studies (forthcoming), forthcoming.

Brunnermeier, M. K.; C. Gollier; and J. A. Parker. "Optimal Beliefs, Asset Prices, and the Preference for Skewed Returns." The American Economic Review, 97 (2007), 159-165.

Campbell, J.; M. Lettau; B. Malkiel; and Y. Xu. "Have Individual Stocks Become More Volatile? An Empirical Exploration of Idiosyncratic Risk." The Journal of Finance, 56 (2001), 1-43.

Cuzick, J. "A Strong Law for Weighted Sums of I.I.D. Random Variables." Journal of Theoretical Probability, 8 (1995), 625-641.

Fama, E., and K. French. "Common Risk Factors in the Returns on Stocks and Bonds." Journal of Financial Economics, 33 (1993), 3-56.

French, K. R.; G. W. Schwert; and R. F. Stambaugh. "Expected Stock Returns and Volatility." Journal of Financial Economics, 19 (1987), 3-29.

Fu, F. "Idiosyncratic Risk and the Cross-Section of Expected Stock Returns." Journal of Financial Economics, 91 (2009), 24-37. 
Goyal, A., and P. Santa-Clara. "Idiosyncratic Risk Matters!" The Journal of Finance, 58 (2003), 975-1008.

Groeneveld, R., and G. Meeden. "Measuring Skewness and Kurtosis." The Statistician, 33 (1984), 391-399.

Guo, H., and R. Savickas. "Average Idiosyncratic Volatility In G7 Countries." The Review of Financial Studies, 21 (2008), 1259-1296.

Hinkley, D. "On Power Transformations to Symmetry." Biometrika, 62 (1975), 101-111.

Huang, W.; Q. Liu; S. Rhee; and L. Zhang. "Return Reversals, Idiosyncratic Risk, and Expected Returns." Review of Financial Studies, 23 (2010), 147-168.

Kachman, S. D. "Distribution of Linear Transformations and Quadratic Forms." (1999). Working Paper, University of Nebraska, Lincoln.

Kapadia, N. "The Next Microsoft ? Skewness, Idiosyncratic Volatility, and Expected Returns." (2009). Working Paper, University of North Carolina at Chapel Hill.

Kim, T., and H. White. "On More Robust Estimation of Skewness and Kurtosis." Finance Research Letters, 1 (2004), 56-73.

Levy, H. "Equilibrium in an Imperfect Market: A Constraint on the Number of Securities in the Portfolio." American Economic Review, 68 (1978), 643-658.

Malkiel, B., and Y. Xu. "Idiosyncratic Risk and Security Returns." (2002). Working Paper, University of Texas at Dallas.

Merton, R. "On the Pricing of Corporate Debt: The Risk Structure of Interest Rates." The Journal of Finance, 29 (1974), 449-470.

Merton, R. "A Simple Model of Capital Market Equilibrium with Incomplete Information." The Journal of Finance, 42 (1987), 483-510. 
Mitton, T., and K. Vorkink. "Equilibrium Underdiversification and the Preference for Skewness." Review of Financial Studies, 20 (2007), 1255-1288.

Newey, W., and K. West. "A Simple, Positive Semi-Definite, Heteroskedasticity and Autocorrelation Consistent Covariance Matrix." Econometrica: Journal of the Econometric Society, 55 (1987), 703-708.

Pontiff, J. "Costly Arbitrage and the Myth of Idiosyncratic Risk." Journal of Accounting and Economics, 42 (2006), 35-52.

Ross, S. "The Arbitrage Theory of Capital Asset Pricing." Journal of Economic Theory, 13 (1976), 341-360.

Sharpe, W. "A Simplified Model for Portfolio Analysis." Management Science, 9 (1963), $277-293$.

Sung, S. H. "Strong Laws for Weighted Sums of I.I.D. Random Variables." Bull. Korean Math. Society, 39 (2002), 607-615.

Tédongap, R. "Consumption Volatility and the Cross-Section of Stock Returns." (2010). Working Paper, Stockholm School of Economics.

Wei, S., and C. Zhang. "Idiosyncratic Risk Does Not Matter: A Re-examination of the Relationship between Average Returns and Average Volatilities." Journal of Banking and Finance, 29 (2005), 603-621.

Welch, I., and A. Goyal. "A Comprehensive Look at the Empirical Performance of Equity Premium Prediction." Review of Financial Studies, 21 (2008), 1455-1508. 


\section{A Proof of Proposition 1}

Consider the factor model decomposition

$$
r_{t}^{\left(w_{t}\right)}=\sum_{i=1}^{N_{t}} w_{i t} \beta_{i t} F_{t}+\sum_{i=1}^{N_{t}} w_{i t} \varepsilon_{i t}
$$

and

$$
r_{i t}-r_{t}^{\left(w_{t}\right)}=\left(\beta_{i t}-\sum_{j=1}^{N_{t}} w_{j t} \beta_{j t}\right) F_{t}+\varepsilon_{i t}-\sum_{j=1}^{N_{t}} w_{j t} \varepsilon_{j t}
$$

Under the homogeneous betas assumption, we have

$$
r_{i t}-r_{t}^{\left(w_{t}\right)}=\varepsilon_{i t}-\sum_{j=1}^{N_{t}} w_{j t} \varepsilon_{j t}
$$

and therefore

$$
\left[r_{i t}-r_{t}^{\left(w_{t}\right)}\right]^{2}=\varepsilon_{i t}^{2}+\left(\sum_{j=1}^{N_{t}} w_{j t} \varepsilon_{j t}\right)^{2}-2 \varepsilon_{i t} \sum_{j=1}^{N_{t}} w_{j t} \varepsilon_{j t}
$$

so that

$$
\begin{aligned}
C S V_{t}^{\left(w_{t}\right)} & =\sum_{i=1}^{N_{t}} w_{i t}\left(r_{i t}-r_{t}^{\left(w_{t}\right)}\right)^{2} \\
& =\sum_{i=1}^{N_{t}} w_{i t} \varepsilon_{i t}^{2}+\left(\sum_{j=1}^{N_{t}} w_{j t} \varepsilon_{j t}\right)^{2}-2 \sum_{i=1}^{N_{t}} \sum_{j=1}^{N_{t}} w_{j t} w_{i t} \varepsilon_{i t} \varepsilon_{j t} \\
& =\sum_{i=1}^{N_{t}} w_{i t} \varepsilon_{i t}^{2}-\left(\sum_{i=1}^{N_{t}} w_{j t} \varepsilon_{j t}\right)^{2}
\end{aligned}
$$

We now argue that the term $\sum_{i=1}^{N_{t}} w_{j t} \varepsilon_{j t}$ converges to 0 for increasingly large numbers of stocks. To show this, we need to use recent results regarding the Marcinkiewcz-Zygmund strong law of large numbers for weighted sums of i.i.d. variables (see Sung (2002)):

$$
\frac{1}{N} \sum_{i=1}^{N} a_{N i} X_{i} \underset{N \rightarrow \infty}{\longrightarrow} 0 \text { almost surely }
$$


when $\left\{X, X_{N}, N \geq 1\right\}$ is a sequence of i.i.d. random variables with $E(X)=0, E|X|^{2}<\infty$ and $\left\{a_{N i}, 1 \leq i \leq N, N \geq 1\right\}$ is an array of constants satisfying ${ }^{38}$

$$
\sum_{i=1}^{N} a_{N i}=O\left(\frac{1}{N}\right)
$$

Here we take $a_{N i} \equiv w_{i t}$ and $X_{i} \equiv \varepsilon_{i t}$ at all dates $t$. Thus, for a positive weighting scheme satisfying condition (A-3), it follows from the strong law of large numbers for weighted sums of i.i.d. variables that:

$$
\sum_{i=1}^{N_{t}} w_{i t} \varepsilon_{i t} \underset{N_{t} \rightarrow \infty}{\longrightarrow} 0 \text { a.s. }
$$

Using similar arguments, and the homogeneous idiosyncratic second moment assumption, $E\left[\varepsilon_{i t}^{2}\right] \equiv \sigma_{\varepsilon}^{2}(t)$, we obtain that for a strictly positive weighting scheme, $w_{t}$, and i.i.d. $\varepsilon_{i}$

$$
\sum_{i=1}^{N_{t}} w_{i t} \varepsilon_{i t}^{2} \underset{N_{t} \rightarrow \infty}{\longrightarrow} \sigma_{\varepsilon}^{2}(t) \text { almost surely }
$$

Using these results, we finally have that:

$$
C S V_{t}^{\left(w_{t}\right)}=\sum_{i=1}^{N_{t}} w_{i t}\left(r_{i t}-r_{t}^{\left(w_{t}\right)}\right)^{2} \underset{N_{t} \rightarrow \infty}{\longrightarrow} \sigma_{\varepsilon}^{2}(t) \text { almost surely }
$$

\section{B Properties of the CSV Estimator}

\section{A Bias of the CSV Estimator}

Under the factor model decomposition (1) and equation (2) and using the homogeneous beta assumption, we have:

\footnotetext{
${ }^{38}$ See corollary 2 in Sung (2002) (with $p=q=2$ ). Note that the convergence result holds under slightly weaker assumptions (see Cuzick (1995) or corollary 2 from Sung (2002)).
} 


$$
r_{i t}-r_{t}^{\left(w_{t}\right)}=\left(\beta_{i t}-\sum_{j=1}^{N_{t}} w_{j t} \beta_{j t}\right) F_{t}+\varepsilon_{i t}-\sum_{j=1}^{N_{t}} w_{j t} \varepsilon_{j t}=\varepsilon_{i t}-\sum_{j=1}^{N_{t}} w_{j t} \varepsilon_{j t}
$$

Replacing result (B-1) in equation (3) we have as before:

$$
C S V_{t}^{\left(w_{t}\right)}=\sum_{i=1}^{N_{t}} w_{i t} \varepsilon_{i t}^{2}-\sum_{i=1}^{N_{t}} \sum_{j=1}^{N_{t}} w_{j t} w_{i t} \varepsilon_{i t} \varepsilon_{j t}
$$

By definition of a strict factor model, $E\left[\varepsilon_{i t} \varepsilon_{j t}\right]=0$ for $i \neq j$, and $E\left(\varepsilon_{i t}^{2}\right)=\sigma_{\varepsilon_{i}}^{2}$. Applying the expectation operator in equation (B-2) we get:

$$
E\left[C S V_{t}^{\left(w_{t}\right)}\right]=\sum_{i=1}^{N_{t}} w_{i t} \sigma_{\varepsilon_{i}}^{2}(t)-\sum_{i=1}^{N_{t}} w_{i t}^{2} \sigma_{\varepsilon_{i}}^{2}(t)
$$

The second term in (B-3) implies that the CSV would tend to underestimate the average idiosyncratic variance. Considering the equal-weighted scheme where $w_{i t}=1 / N_{t} \forall i,(\mathrm{~B}-3)$ simplifies into

$$
E\left[C S V_{t}^{E W}\right]=\left(1-\frac{1}{N_{t}}\right) \frac{1}{N_{t}} \sum_{i=1}^{N_{t}} \sigma_{\varepsilon_{i}}^{2}(t)
$$

and we obtain, as $N_{t}$ goes to infinity:

$$
E\left[C S V_{t}^{E W}\right]-\frac{1}{N_{t}} \sum_{i=1}^{N_{t}} \sigma_{\varepsilon_{i t}}^{2} \rightarrow 0
$$

\section{B Variance of the CSV Estimator}

Let $w_{t}$ and $\varepsilon_{t}$ be column vectors of the weighting scheme and residuals respectively and $\Omega_{t}=w_{t} w_{t}^{\prime}, \Lambda_{t}=\operatorname{diag}\left(w_{t}\right), N_{t} \times N_{t}$ matrices, and denote $\Sigma^{\varepsilon}$ the variance covariance matrix of the residuals, which is diagonal for a strict factor model. 
For a finite number of stocks in the case where $F_{t} \neq r^{\left(w_{t}\right)}$, we have from equation (B-2):

$$
C S V_{t}^{\left(w_{t}\right)}=\sum_{i=1}^{N_{t}} w_{i t} \varepsilon_{i t}^{2}-\sum_{i=1}^{N_{t}} \sum_{j=1}^{N_{t}} w_{j t} w_{i t} \varepsilon_{i t} \varepsilon_{j t}
$$

Letting $Q_{t}=\Lambda_{t}-\Omega_{t}, C S V_{t}$ can be written in matrix form, as follows:

$$
C S V_{t}^{\left(w_{t}\right)}=\varepsilon_{t}^{\prime} Q_{t} \varepsilon_{t}
$$

Using the quadratic structure of the CSV and assuming normal residuals, we have (see for instance Kachman (1999)) $)^{39}$ :

$$
\operatorname{Var}\left(\varepsilon_{t}^{\prime} Q_{t} \varepsilon_{t}\right)=2 \operatorname{tr}\left(Q_{t} \Sigma_{t}^{\varepsilon} Q_{t} \Sigma_{t}^{\varepsilon}\right)
$$

Under the assumption of a strict factor model, i.e. $\rho_{i j t}^{\varepsilon}=0 \forall i \neq j$, equation (B-5) simplifies to:

$$
\operatorname{Var}\left(C S V_{t}^{\left(w_{t}\right)}\right)=2 \sum_{i=1}^{N_{t}} \sigma_{\varepsilon_{i t}}^{4} w_{i t}^{2}\left(1-w_{i t}\right)^{2}+2 \sum_{i=1}^{N_{t}} \sum_{j \neq i}^{N_{t}} w_{i t}^{2} w_{j t}^{2} \sigma_{\varepsilon_{i t}}^{2} \sigma_{\varepsilon_{j t}}^{2}
$$

Assuming an upper bound for the individual idiosyncratic variances, denoted as $\bar{\sigma}_{\varepsilon_{t}}^{2}$ equation (B-6) yields to the following inequality (replacing each variance for its upper bound)

$$
\operatorname{Var}\left(C S V_{t}^{\left(w_{t}\right)}\right)<2 \bar{\sigma}_{\varepsilon_{t}}^{4}\left(\left(\sum_{i=1}^{N_{t}} w_{i t}^{2}\right)^{2}+\sum_{i=1}^{N_{t}} w_{i t}^{2}-2 \sum_{i=1}^{N_{t}} w_{i t}^{3}\right) .
$$

\footnotetext{
${ }^{39}$ The operator tr stands for the trace of a matrix, which is the sum of the diagonal terms.
} 
When $w_{t}=1 / N_{t}$, equation (B-7) simplifies to

$$
\operatorname{Var}\left(C S V_{t}^{\left(w_{t}\right)}\right)<2 \bar{\sigma}_{\varepsilon_{t}}^{4}\left(\frac{N_{t}-1}{N_{t}^{2}}\right)<2 \bar{\sigma}_{\varepsilon_{t}}^{4}\left(\frac{1}{N_{t}}\right)
$$

For a large number of stocks,

$$
\operatorname{Var}\left(C S V_{t}^{\left(w_{t}\right)}\right) \longrightarrow 0
$$

\section{Relaxing the Assumption of Homogenous Betas}

The assumption that $\beta_{i t}=\beta_{t}$ for all $i$ is obviously a simplistic one and is done only for exposure purposes. Starting with the single factor decomposition on the definition of the CSV we have:

$$
\begin{aligned}
C S V_{t}^{\left(w_{t}\right)} & =\sum_{i=1}^{N_{t}} w_{i t}\left(r_{i t}-r_{t}^{\left(w_{t}\right)}\right)^{2} \\
& =\sum_{i=1}^{N_{t}} w_{i t}\left[\left(\beta_{i t}-\sum_{j=1}^{N_{t}} w_{j t} \beta_{j t}\right) F_{t}+\varepsilon_{i t}-\sum_{i=1}^{N_{t}} w_{j t} \varepsilon_{j t}\right]^{2}
\end{aligned}
$$

After simple rearrangement of terms we get:

$$
\begin{aligned}
C S V_{t}^{\left(w_{t}\right)} & =F_{t}^{2} \sum_{i=1}^{N_{t}} w_{i t}\left(\beta_{i t}-\sum_{j=1}^{N_{t}} w_{j t} \beta_{j t}\right)^{2}+\sum_{i=1}^{N_{t}} w_{i t} \varepsilon_{i t}^{2}-\sum_{i=1}^{N_{t}} \sum_{j=1}^{N_{t}} w_{j t} w_{i t} \varepsilon_{i t} \varepsilon_{j t} \\
& +2 F_{t} \sum_{i=1}^{N_{t}} w_{i t} \varepsilon_{i t}\left(\beta_{i t}-\sum_{j=1}^{N_{t}} w_{j t} \beta_{j t}\right)
\end{aligned}
$$

Applying the expectation operator and assuming a strict factor model, the last expression 
simplifies so as to yield:

$$
E\left[C S V_{t}^{\left(w_{t}\right)}\right]=\sum_{i=1}^{N_{t}} w_{i t} \sigma_{\varepsilon_{i} t}^{2}-\sum_{i=1}^{N_{t}} w_{i t}^{2} \sigma_{\varepsilon_{i} t}^{2}+E\left[F_{t}^{2} C S V_{t}^{\beta}\right]
$$




\section{Tables and Figures}

Table 1: Estimates of the Biases due to the Cross-Sectional Dispersion of Betas and Weight Concentration: This table contains a summary of the distribution of the following time series: the cross-sectional dispersion of betas $C S V_{t}^{\beta}$, estimated with respect to the CAPM at the end of every month using daily returns; the average idiosyncratic variance $\sigma_{\varepsilon_{t}}^{2}$ with respect to the CAPM; the product of the average return of the market portfolio squared, $F_{t}^{2}$, and the beta dispersion, $C S V_{t}^{\beta}$; the proportion of the product $F_{t}^{2} C S V_{t}^{\beta}$ to $\sigma_{\varepsilon_{t}}^{2}$ and the proportion of $\sum w_{i t}^{2} \sigma_{\varepsilon_{i t}}^{2}$ to $\sigma_{\varepsilon_{t}}^{2}$. The upper panel corresponds to the equal-weight scheme $\left(C S V^{E W}\right)$ and the lower panel to the market-cap weighting $\left(C S V^{C W}\right)$. All figures are daily. The period is from July 1963 to December 2006.

\begin{tabular}{cccccc}
\hline Equal-Weighted & $Q_{2.5}$ & $Q_{25}$ & $Q_{50}$ & $Q_{75}$ & $Q_{97.5}$ \\
\hline$C S V_{t}^{\beta}$ & 0.282 & 0.970 & 1.563 & 3.022 & 11.437 \\
$\sigma_{\varepsilon_{t}}^{2}(\%)$ & 0.043 & 0.065 & 0.103 & 0.241 & 0.485 \\
$F_{t}^{2} C S V_{t}^{\beta}(\%)$ & $6.57 \mathrm{e}-07$ & $6.92 \mathrm{e}-05$ & $3.84 \mathrm{e}-04$ & 0.001 & 0.005 \\
$\frac{F_{t}^{2} C S V^{\beta}}{\sigma_{\varepsilon_{t}}^{2}}(\%)$ & 0.001 & 0.078 & 0.348 & 0.890 & 3.240 \\
$\frac{\sum w_{i t}^{2} \sigma_{\varepsilon_{i t}}^{2}}{\sigma_{\varepsilon_{t}}^{2}}(\%)$ & 0.014 & 0.020 & 0.030 & 0.054 & 0.154 \\
\hline Cap-Weighted & $Q_{2.5}$ & $Q_{25}$ & $Q_{50}$ & $Q_{75}$ & $Q_{97.5}$ \\
\hline$C S V_{t}^{\beta}$ & 0.075 & 0.309 & 0.451 & 0.704 & 3.079 \\
$\sigma_{\varepsilon_{t}}^{2}(\%)$ & 0.009 & 0.020 & 0.030 & 0.042 & 0.153 \\
$F_{t}^{2} C S V_{t}^{\beta}(\%)$ & $1.83 \mathrm{e}-07$ & $2.30 \mathrm{e}-05$ & $1.09 \mathrm{e}-04$ & $2.77 \mathrm{e}-04$ & 0.001 \\
$\frac{F_{t}^{2} C S V^{\beta}}{\sigma_{\varepsilon_{t}}^{2}}(\%)$ & $4.85 \mathrm{e}-04$ & 0.080 & 0.351 & 0.930 & 3.472 \\
$\frac{\sum w_{i t}^{2} \sigma_{\varepsilon_{i t}}^{2}}{\sigma_{\varepsilon_{t}}^{2}}(\%)$ & 0.173 & 0.281 & 0.426 & 0.637 & 1.463 \\
\hline
\end{tabular}


Table 2: Total Bias Associated with CSV: This table reports the results of the regression $C S V_{t}^{w_{t}}=$ bias $+\psi \sigma_{\text {model }}^{2}\left(w_{t}\right)+\zeta_{t}$, where $\sigma_{\text {model }}^{2}\left(w_{t}\right)$ represents monthly estimates of the weighted average idiosyncratic variance estimated using the corresponding model (either CAPM or $\mathrm{FF}$ ). The average measures and the $C S V$ are computed with either the capweighted scheme $(\mathrm{CW})$ or the equal-weighted one (EW). The period is from July 1963 to December 2006.

\begin{tabular}{ccccc}
\hline & $C A P M^{E W}$ & $F F^{E W}$ & $C A P M^{C W}$ & $F F^{C W}$ \\
\hline Bias & $1.29 \mathrm{e}-05$ & $2.23 \mathrm{e}-05$ & $-2.09 \mathrm{e}-05$ & $-3.74 \mathrm{e}-05$ \\
NW t-stat & $(1.986)$ & $(2.382)$ & $(-2.849)$ & $(-4.767)$ \\
$\psi$ & 0.983 & 0.988 & 1.125 & 1.242 \\
NW t-stat & $(153.819)$ & $(100.162)$ & $(39.259)$ & $(39.226)$ \\
$\bar{R}^{2}(\%)$ & 99.866 & 99.503 & 98.946 & 97.117 \\
\hline
\end{tabular}




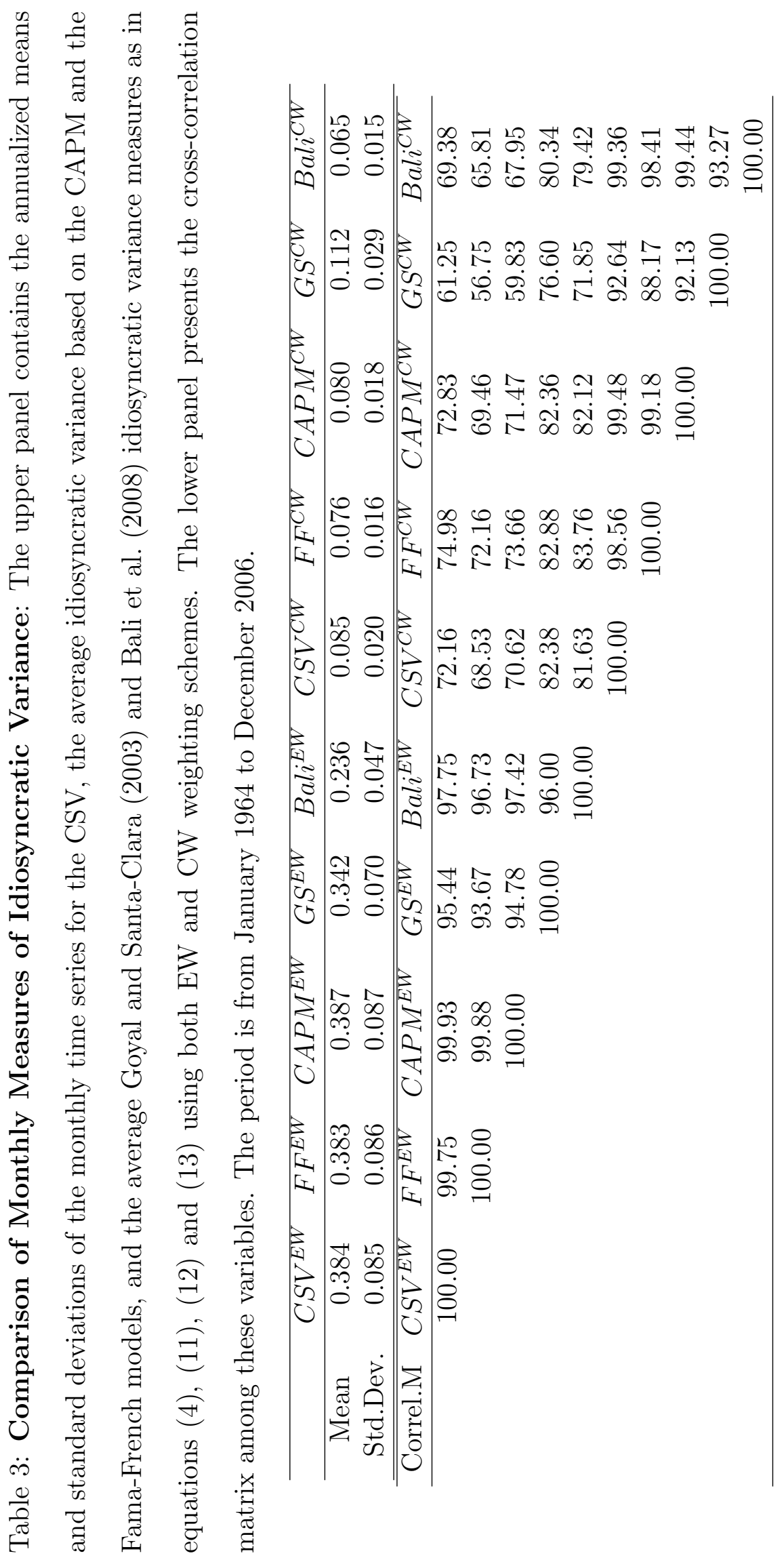


Table 4: Comparison of Daily Measures of Idiosyncratic Variance: The upper panel contains the annualized means and standard deviations of the daily time series for the CSV and the average idiosyncratic variance based on the Fama-French model as in equations (4) and (11) using both weighting schemes. The lower panel presents the cross-correlation matrix among these variables. The period is from January 1964 to December 2006.

\begin{tabular}{ccccc}
\hline & $C S V^{E W}$ & $F F^{E W}$ & $C S V^{C W}$ & $F F^{C W}$ \\
\hline Mean & 0.384 & 0.383 & 0.085 & 0.078 \\
Std.Dev. & 0.021 & 0.019 & 0.005 & 0.004 \\
\hline Correlation & $C S V^{E W}$ & $F F^{E W}$ & $C S V^{C W}$ & $F F^{C W}$ \\
\hline & 100.00 & 82.63 & 60.33 & 63.96 \\
& & 100.00 & 52.12 & 72.55 \\
& & & 100.00 & 73.95 \\
& & & & 100.00 \\
\hline
\end{tabular}


Table 5: Idiosyncratic Volatility - Regimes and Relations with Macroeconomic and Financial Variables: Panel A reports the parameter estimates of the regime-switching model specified in equation 15, first at the monthly frequency for the equally-weighted CSV and for the average idiosyncratic variance based on the FF model as in equations (4) and (11), then at the daily frequency for the CSV. $\mu_{i}$ is the average level of the variable on regime $i, \sigma_{i}$ is the standard deviation level of the variable on regime $i, \phi$ is the autocorrelation coefficient, $\mathrm{p}$ and $\mathrm{q}$ are the probabilities of remaining in regimes 1 and 2 respectively. The estimation period is from $01 / 1964$ to $12 / 2006$. In Panel $\mathrm{B}$, we run the regression $C S V_{t}^{E W}=$

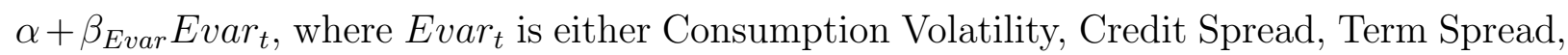
Inflation volatility and Risk-free rate. The sample period is $01 / 1990$ to $12 / 2006$.

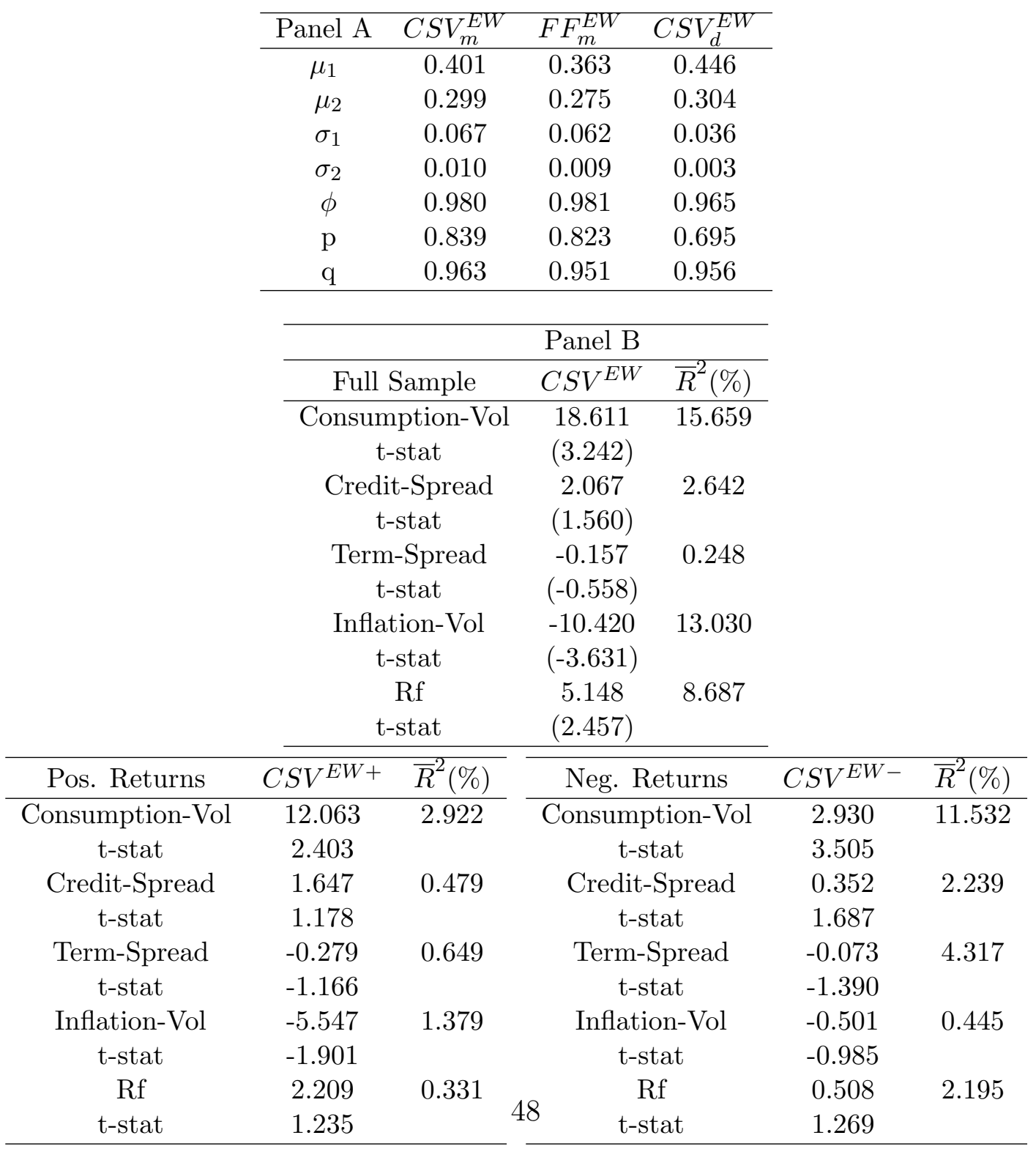


Table 6: Monthly Predictability of Market Returns by Two Measures of Idiosyncratic Variance (Cross-Sectional Variance and CAPM-based): The upper panel presents the results of a one-month ahead predictive regression of the monthly cap-weighted market excess returns, denoted by $r^{C W}$, by the monthly lagged equal-weighted CAPM-based average idiosyncratic variance and $C S V^{E W}$ for three sample periods. The second panel reports corresponding results for predicting the monthly equal-weighted market excess returns, denoted by $r^{E W}$, by the monthly lagged equal-weighted CAPM-based average idiosyncratic variance and $C S V^{E W}$. In the third panel, the monthly cap-weighted market excess returns, ${ }_{r}^{C W}$, are predicted by the monthly lagged CAPM-based cap-weighted idiosyncratic variance and $C S V^{C W}$. CAPM refers to the average idiosyncratic variance derived from the CAPM, estimated using one month of daily data and $C S V$ is the average of the daily cross-sectional variance over each month. The intercept, the regression coefficient of the corresponding lagged idiosyncratic variance, the Newey-West corrected t-stats and the adjusted coefficient of determination denoted by $\bar{R}^{2}$ are reported. The sample periods are 1963:08 - 1999:12, 1963:08 - 2001:12 and 1963:08 - 2006:12.

\begin{tabular}{ccccccc}
\hline Monthly series & \multicolumn{2}{c}{$1963: 08-1999: 12$} & \multicolumn{2}{c}{$1963: 08-2001: 12$} & \multicolumn{2}{c}{$1963: 08-2006: 12$} \\
\hline Forecasting $r^{C W}$ & $C A P M^{E W}$ & $C S V^{E W}$ & $C A P M^{E W}$ & $C S V^{E W}$ & $C A P M^{E W}$ & $C S V^{E W}$ \\
\hline Intercept & -0.001 & -0.002 & 0.001 & 0.001 & 0.002 & 0.002 \\
NW t-stat & $(-0.424)$ & $(-0.479)$ & $(0.228)$ & $(0.264)$ & $(0.586)$ & $(0.617)$ \\
Coefficient & 0.241 & 0.250 & 0.123 & 0.120 & 0.090 & 0.087 \\
NW t-stat & $(3.543)$ & $(3.609)$ & $(1.356)$ & $(1.247)$ & $(1.055$ & $(0.964)$ \\
$\bar{R}^{2}(\%)$ & 1.336 & 1.365 & 0.275 & 0.233 & 0.072 & 0.044 \\
\hline Forecasting $r^{E W}$ & $C A P M^{E W}$ & $C S V^{E W}$ & $C A P M^{E W}$ & $C S V^{E W}$ & $C A P M^{E W}$ & $C S V^{E W}$ \\
\hline Intercept & $4.51 \mathrm{e}-04$ & $3.31 \mathrm{e}-04$ & $-1.67 \mathrm{e}-04$ & $-1.06 \mathrm{e}-05$ & 0.001 & 0.001 \\
NW t-stat & $(0.086)$ & $(0.063)$ & $(-0.033)$ & $(-0.002)$ & $(0.241)$ & $(0.270)$ \\
Coefficient & 0.247 & 0.254 & 0.238 & 0.235 & 0.217 & 0.215 \\
NW t-stat & $(2.175)$ & $(2.189)$ & $(2.395)$ & $(2.329)$ & $(2.331)$ & $(2.271)$ \\
$\bar{R}^{2}(\%)$ & 0.774 & 0.773 & 0.885 & 0.824 & 0.726 & 0.678 \\
\hline Forecasting $r^{C W}$ & $C A P M^{C W}$ & $C S V^{C W}$ & $C A P M^{C W}$ & $C S V^{C W}$ & $C A P M^{C W}$ & $C S V^{C W}$ \\
\hline Intercept & 0.001 & 0.001 & 0.007 & 0.007 & 0.007 & 0.008 \\
NW t-stat & $(0.150)$ & $(0.334)$ & $(2.226)$ & $(2.459)$ & $(2.551)$ & $(2.823)$ \\
Coefficient & 0.856 & 0.688 & -0.356 & -0.373 & -0.404 & -0.421 \\
NW t-stat & $(1.192)$ & $(0.995)$ & $(-0.871)$ & $(-1.081)$ & $(-1.080)$ & $(-1.334)$ \\
$\bar{R}^{2}(\%)$ & 0.128 & 0.043 & -0.037 & 0.038 & 0.035 & 0.123 \\
\hline
\end{tabular}


Table 7: Daily predictability of Market Returns by Cross-Sectional Variance:

The upper panel presents the results of a one-day ahead predictive regression of the equalweighted daily market excess returns, denoted by $r^{E W}$, on the daily lagged equal-weighted cross-sectional variance denoted by $C S V^{E W}$ estimated as in equation (4) for three sample periods. The lower panel presents the results of the predictive regression of the cap-weighted daily excess market returns using the cap-weighted CSV. The intercept, the regression coefficient corresponding to the CSV, the Newey-West corrected t-stats (30 lags) and the adjusted coefficient of determination denoted by $\bar{R}^{2}$ are reported. The sample periods are 1963:07 to $1999: 12,1963: 07$ to $2001: 12$ and 1963:07 to 2006:12.

\begin{tabular}{cccc}
\hline Daily series & $63: 07-99: 12$ & $63: 07-01: 12$ & $63: 07-06: 12$ \\
\hline Forecasting $r^{E W}$ & $C S V^{E W}$ & $C S V^{E W}$ & $C S V^{E W}$ \\
\hline Intercept & $-1.58 \mathrm{e}-04$ & $-1.40 \mathrm{e}-04$ & $-1.29 \mathrm{e}-05$ \\
NW t-stat & $(-0.785)$ & $(-0.714)$ & $(-0.071)$ \\
Coefficient & 0.544 & 0.483 & 0.411 \\
NW t-stat & $(4.711)$ & $(4.515)$ & $(4.000)$ \\
$\bar{R}^{2}(\%)$ & 0.883 & 0.788 & 0.573 \\
\hline Forecasting $r^{C W}$ & $C S V^{C W}$ & $C S V^{C W}$ & $C S V^{C W}$ \\
\hline Intercept & -0.001 & $-1.88 \mathrm{e}-04$ & $-1.65 \mathrm{e}-04$ \\
NW t-stat & $(-3.521)$ & $(-0.791)$ & $(-0.737)$ \\
Coefficient & 3.404 & 1.189 & 1.151 \\
NW t-stat & $(5.919)$ & $(1.948)$ & $(1.966)$ \\
$\bar{R}^{2}(\%)$ & 0.831 & 0.220 & 0.186 \\
\hline
\end{tabular}


Table 8: Daily and Monthly Return Predictability by Cross-Sectional Variance Controlling for Macroeconomic Variables: The two upper panels include the multivariate regression results for daily predictions of the equal-weighted or cap-weighted market returns using the equal-weighted CSV (first panel) or the cap-weighted CSV (second panel) and a set of macroeconomic variables as predictors. The two lower panels report the corresponding monthly predictions. The set of macroeconomic variables are the aggregate dividend yield (DIV), the term spread (TERM), the default or credit spread (DEF) and the relative T-bill rate (RREL). The sample period is from July 1963 to December 2006.

\begin{tabular}{cccc}
\hline Forecasting $r^{E W}-$ Daily & Coeff & NW t-stat & $\bar{R}^{2}(\%)$ \\
\hline$C S V^{E W}$ & 0.380 & $(3.408)$ & 1.363 \\
RREL & -0.056 & $(-3.861)$ & \\
DIV & 0.013 & $(1.434)$ & \\
TERM & 0.010 & $(0.743)$ & \\
\hline \hline Forecasting $r^{C W}-$ Daily & Coeff & NW t-stat & $\bar{R}^{2}(\%)$ \\
\hline$C S V^{C W}$ & 1.337 & $(2.012)$ & 0.473 \\
RREL & -0.036 & $(-3.232)$ & \\
DIV & 0.011 & $(1.438)$ & \\
TERM & 0.010 & $(0.961)$ & \\
\hline Forecasting $r^{E W}-$ Monthly & Coeff & NW t-stat & $\bar{R}^{2}(\%)$ \\
\hline$C S V^{E W}$ & 0.275 & $(2.262)$ & 5.670 \\
RREL & -1.062 & $(-3.672)$ & \\
DIV & 0.647 & $(1.531)$ & \\
TERM & 0.078 & $(0.370)$ & \\
DEF & -0.034 & $(-0.036)$ & \\
\hline Forecasting $r^{C W}-$ Monthly & Coeff & NW t-stat & $\bar{R}^{2}(\%)$ \\
\hline$C S V^{C W}$ & -0.400 & $(-1.106)$ & 3.007 \\
RREL & -0.701 & $(-3.497)$ & \\
DIV & 0.067 & $(0.256)$ & \\
TERM & 0.132 & $(0.959)$ & \\
DEF & 0.014 & $(0.021)$ & \\
\hline
\end{tabular}


Table 9: Daily and Monthly Return Predictability with and without Market

Volatility: This table presents summary statistics for three predictive regressions. The two upper panels correspond to daily and monthly predictions of the equal-weighted broad market index using equal-weighted CSV and the realized variance of the equal-weighted broad market index, while the two lower panels include the corresponding statistics for the cap-weighted measures for both returns and CSV. In each panel, the first row corresponds to the regression $r_{t}^{w}=\alpha+\beta C S V_{t}^{w}+\epsilon_{t}$, the second row to $r_{t}^{w}=\alpha+\vartheta \operatorname{Var}\left(r_{t}^{w}\right)+\epsilon_{t}$, and the third one to $r_{t}^{w}=\alpha+\beta C S V_{t}^{w}+\vartheta \operatorname{Var}\left(r_{t}^{w}\right)+\epsilon_{t}$. The sample period is from July 1963 to December 2006.

\begin{tabular}{cccccccc}
\hline Daily Estimates & Intercept & T-stat & $C S V^{E W}$ & T-stat & $\operatorname{Var}\left(r^{E W}\right)$ & T-stat & $\bar{R}^{2}(\%)$ \\
\hline Forecasting $r^{E W}$ & $-1.29 \mathrm{e}-05$ & $(-0.071)$ & 0.411 & $(4.000)$ & & & 0.573 \\
Forecasting $r^{E W}$ & 0.001 & $(4.928)$ & & & -2.437 & $(-0.976)$ & 0.034 \\
Forecasting $r^{E W}$ & $1.19 \mathrm{e}-04$ & $(0.629)$ & 0.470 & $(4.672)$ & -5.038 & $(-2.226)$ & 0.737 \\
\hline Monthly Estimates & Intercept & T-stat & $C S V^{E W}$ & T-stat & $\operatorname{Var}\left(r^{E W}\right)$ & T-stat & $\bar{R}^{2}(\%)$ \\
\hline Forecasting $r^{E W}$ & 0.001 & $(0.270)$ & 0.215 & $(2.271)$ & & & 0.678 \\
Forecasting $r^{E W}$ & 0.008 & $(2.673)$ & & & 0.240 & $(0.182)$ & -0.185 \\
Forecasting $r^{E W}$ & 0.001 & $(0.324)$ & 0.226 & $(2.206)$ & -0.478 & $(-0.394)$ & 0.515 \\
\hline \hline Daily Estimates & Intercept & T-stat & $C S V^{C W}$ & T-stat & $\operatorname{Var}\left(r^{C W}\right)$ & T-stat & $\bar{R}^{2}(\%)$ \\
\hline Forecasting $r^{C W}$ & $-1.65 \mathrm{e}-04$ & $(-0.737)$ & 1.151 & $(1.966)$ & & & 0.186 \\
Forecasting $r^{C W}$ & $2.10 \mathrm{e}-05$ & $(0.183)$ & & & 2.680 & $(2.003)$ & 0.068 \\
Forecasting $r^{C W}$ & $-1.76 \mathrm{e}-04$ & $(-0.937)$ & 1.084 & $(1.298)$ & 0.447 & $(0.198)$ & 0.179 \\
\hline Monthly Estimates & Intercept & T-stat & $C S V^{C W}$ & T-stat & $\operatorname{Var}\left(r^{C W}\right)$ & T-stat & $\bar{R}^{2}(\%)$ \\
\hline Forecasting $r^{C W}$ & 0.008 & $(2.823)$ & -0.421 & $(-1.334)$ & & & 0.123 \\
Forecasting $r^{C W}$ & 0.005 & $(2.636)$ & & & -0.418 & $(-0.569)$ & -0.116 \\
Forecasting $r^{C W}$ & 0.008 & $(2.815)$ & -0.459 & $(-1.054)$ & 0.130 & $(0.113)$ & -0.065 \\
\hline
\end{tabular}


Table 10: Predictability Regression on Market Returns with Right and Left CSV

Measures, and Skewness: In the upper panel, we report the results of daily and monthly predictive regressions of the excess equal-weighted and cap-weighted portfolio returns, denoted respectively by $r^{E W}$ and $r^{C W}$. We use as predictors the corresponding daily or monthly measures of the returns cross-sectional variance to the right and the left of the cross-sectional distribution mean, denoted as $C S V^{+}$and $C S V^{-}$respectively. In the lower panel, we report results for similar regressions with the returns cross-sectional skewness as the predictive variable, at the daily and monthly frequencies. We include the intercept, the regression coefficients and the Newey-West corrected t-stats, as well as the adjusted coefficient of determination denoted by $\bar{R}^{2}$. The sample period is from July 1963 to December 2006.

\begin{tabular}{|c|c|c|c|c|c|}
\hline Forecasting $r^{E W}$ & Daily $^{E W}$ & Monthly $^{E W}$ & Forecasting $r^{C W}$ & Daily $^{C W}$ & Monthly ${ }^{C W}$ \\
\hline Intercept & 0.001 & 0.003 & Intercept & $-1.12 \mathrm{e}-04$ & 0.008 \\
\hline NW t-stat & $(3.944)$ & $(0.727)$ & NW t-stat & $(-0.588)$ & $(2.753)$ \\
\hline$C S V^{+}$ & 0.488 & 0.375 & $C S V^{+}$ & 4.942 & 0.071 \\
\hline NW t-stat & $(3.360)$ & $(2.400)$ & NW t-stat & $(3.546)$ & $(0.054)$ \\
\hline$C S V^{-}$ & -1.200 & -0.486 & $C S V^{-}$ & -2.842 & -1.302 \\
\hline NW t-stat & $(-3.551)$ & $(-1.129)$ & NW t-stat & $(-2.736)$ & $(-0.879)$ \\
\hline $\bar{R}^{2}(\%)$ & 1.552 & 1.114 & $\bar{R}^{2}(\%)$ & 0.785 & -0.069 \\
\hline
\end{tabular}

\begin{tabular}{|c|c|c|c|c|c|c|c|}
\hline Daily $-r^{E W}$ & Coeff. & t-stat & $\bar{R}^{2}(\%)$ & Monthly $-r^{E W}$ & Coeff. & t-stat & $\bar{R}^{2}(\%)$ \\
\hline Intercept & 0.001 & $(5.200)$ & 5.345 & Intercept & 0.008 & $(3.403)$ & 3.626 \\
\hline Skewness & 0.004 & $(19.989)$ & & Skewness & 0.004 & $(4.915)$ & \\
\hline Daily $-r^{C W}$ & Coeff. & t-stat & $\bar{R}^{2}(\%)$ & Monthly $-r^{C W}$ & Coeff. & t-stat & $\bar{R}^{2}(\%)$ \\
\hline Intercept & $2.18 \mathrm{e}-004$ & $(2.576)$ & 0.952 & Intercept & 0.006 & $(2.840)$ & 0.047 \\
\hline Skewness & 0.002 & (11.601) & & Skewness & 0.001 & $(1.180)$ & \\
\hline
\end{tabular}




\section{Table 11: Daily and Monthly Predictability of Market Returns with Skewness and}

Macroeconomic Variables: The two upper panel includes the multivariate regression results for daily predictions of the equal-weighted broad market index using the equal-weighted CSV (first panel) or the cap-weighted CSV (second panel), cross-sectional skewness and a set of macroeconomic variables as regressors. The two lower panels report the corresponding monthly predictions. The set of macroeconomic variables are the aggregate dividend yield (DIV), the term spread (TERM), the default or credit spread (DEF) and the relative T-bill rate (RREL). The sample period is from July 1963 to December 2006.

\begin{tabular}{|c|c|c|c|}
\hline Forecasting $r^{E W}$ - Daily & Coeff & NW t-stat & $\bar{R}^{2}(\%)$ \\
\hline$C S V^{E W}$ & 0.331 & $(3.205)$ & 6.081 \\
\hline Skewness & 0.004 & $(19.450)$ & \\
\hline RREL & -0.045 & $(-3.475)$ & \\
\hline DIV & 0.007 & $(0.901)$ & \\
\hline TERM & 0.014 & $(1.142)$ & \\
\hline Forecasting $r^{C W}$ - Daily & Coeff & NW t-stat & $\bar{R}^{2}(\%)$ \\
\hline$C S V^{C W}$ & 1.278 & $(1.912)$ & 1.241 \\
\hline Skewness & 0.002 & $(10.340)$ & \\
\hline RREL & -0.030 & $(-2.916)$ & \\
\hline DIV & 0.009 & $(1.181)$ & \\
\hline TERM & 0.011 & $(1.175)$ & \\
\hline Forecasting $r^{E W}$ - Monthly & Coeff & NW t-stat & $\bar{R}^{2}(\%)$ \\
\hline$C S V^{E W}$ & 0.277 & $(2.403)$ & 7.800 \\
\hline Skewness & 0.003 & $(3.819)$ & \\
\hline RREL & -0.869 & $(-3.108)$ & \\
\hline DIV & 0.546 & $(1.445)$ & \\
\hline TERM & 0.114 & $(0.586)$ & \\
\hline $\mathrm{DEF}$ & 0.043 & $(0.053)$ & \\
\hline Forecasting $r^{C W}$ - Monthly & Coeff & NW t-stat & $\bar{R}^{2}(\%)$ \\
\hline$C S V^{C W}$ & -0.393 & $(-1.092)$ & 2.829 \\
\hline Skewness & $1.47 \mathrm{e}-004$ & $(0.271)$ & \\
\hline RREL & -0.691 & $(-3.426)$ & \\
\hline DIV & 0.064 & $(0.245)$ & \\
\hline TERM & 0.134 & $(0.966)$ & \\
\hline $\mathrm{DEF}$ & 0.015 & $(0.022)$ & \\
\hline
\end{tabular}


Table 12: Pricing of Cross-Sectional Variance: This table displays the average values and Newey-West corrected t-stats for the coefficients in Fama-MacBeth regressions, run every month in the sample, using the betas on the 3 Fama-French factors and on $C S V^{E W}$ for the 100 and 25 size and book-to-market Fama-French equally-weighted (first two tables of each panel) and cap-weighted (last two tables of each panel) portfolios. Panel A uses 1 month of daily data (21 days) to estimate the betas of the Factor model regressions every month while Panel B uses 63 days of daily returns (3 months) to run the Factor model regressions every 21 days. The table also displays the average $R^{2}$ across subsamples of the Fama-MacBeth regressions. The sample period is July 1963 to December 2006.

\section{Panel A}

\begin{tabular}{|c|c|c|c|c|c|c|}
\hline 100-EW Portfolios & Intercept & XMKT & SMB & HML & $C S V^{E W}$ & $R^{2}(\%)$ \\
\hline $\begin{array}{c}\gamma \\
\text { tstat }\end{array}$ & $\begin{array}{c}0.223 \\
(9.222) \\
\end{array}$ & $\begin{array}{c}-0.067 \\
(-4.173) \\
\end{array}$ & $\begin{array}{c}0.029 \\
(2.320) \\
\end{array}$ & $\begin{array}{c}0.048 \\
(3.916) \\
\end{array}$ & $\begin{array}{c}0.005 \\
(2.847) \\
\end{array}$ & 24.657 \\
\hline 25-EW Portfolios & Intercept & XMKT & SMB & $\begin{array}{l}\text { HML } \\
\end{array}$ & $C S V^{E W}$ & $R^{2}(\%)$ \\
\hline $\begin{array}{c}\gamma \\
\text { tstat }\end{array}$ & $\begin{array}{c}0.278 \\
(9.969)\end{array}$ & $\begin{array}{c}-0.133 \\
(-6.447)\end{array}$ & $\begin{array}{c}0.042 \\
(2.480)\end{array}$ & $\begin{array}{c}0.064 \\
(3.927)\end{array}$ & $\begin{array}{c}0.009 \\
(2.703)\end{array}$ & 51.962 \\
\hline 100-CW Portfolios & Intercept & XMKT & SMB & $\begin{array}{l}\text { HML } \\
\end{array}$ & $C S V^{E W}$ & $R^{2}(\%)$ \\
\hline $\begin{array}{c}\gamma \\
\text { tstat }\end{array}$ & $\begin{array}{c}0.155 \\
(6.896)\end{array}$ & $\begin{array}{c}-0.007 \\
(-0.421)\end{array}$ & $\begin{array}{c}0.004 \\
(0.323)\end{array}$ & $\begin{array}{c}0.037 \\
(2.762)\end{array}$ & $\begin{array}{c}0.003 \\
(1.909)\end{array}$ & 24.262 \\
\hline 25-CW Portfolios & Intercept & XMKT & SMB & HML & $C S V^{E W}$ & $R^{2}(\%)$ \\
\hline $\begin{array}{c}\gamma \\
\text { tstat }\end{array}$ & $\begin{array}{c}0.175 \\
(7.417) \\
\end{array}$ & $\begin{array}{c}-0.034 \\
(-1.624) \\
\end{array}$ & $\begin{array}{c}0.010 \\
(0.625) \\
\end{array}$ & $\begin{array}{c}0.048 \\
(2.910) \\
\end{array}$ & $\begin{array}{c}0.004 \\
(1.395) \\
\end{array}$ & 50.815 \\
\hline \multicolumn{7}{|c|}{ Panel B } \\
\hline 100-EW Portfolios & Intercept & XMKT & SMB & HML & $C S V^{E W}$ & $R^{2}(\%)$ \\
\hline $\begin{array}{c}\gamma \\
\text { tstat }\end{array}$ & $\begin{array}{c}0.665 \\
(9.826) \\
\end{array}$ & $\begin{array}{c}-0.278 \\
(-4.866) \\
\end{array}$ & $\begin{array}{c}0.167 \\
(3.676) \\
\end{array}$ & $\begin{array}{c}0.154 \\
(3.398) \\
\end{array}$ & $\begin{array}{c}0.036 \\
(3.422) \\
\end{array}$ & 34.806 \\
\hline 25-EW Portfolios & Intercept & XMKT & SMB & HML & $C S V^{E W}$ & $R^{2}(\%)$ \\
\hline $\begin{array}{c}\gamma \\
\text { tstat }\end{array}$ & $\begin{array}{c}0.844 \\
(9.699) \\
\end{array}$ & $\begin{array}{c}-0.470 \\
(-6.673) \\
\end{array}$ & $\begin{array}{c}0.186 \\
(3.477) \\
\end{array}$ & $\begin{array}{c}0.174 \\
(3.179) \\
\end{array}$ & $\begin{array}{c}0.072 \\
(2.874) \\
\end{array}$ & 61.582 \\
\hline 00-CW Portfolios & Intercept & XMKT & SMB & HML & $C S V^{E W}$ & $R^{2}(\%)$ \\
\hline $\begin{array}{c}\gamma \\
\text { tstat }\end{array}$ & $\begin{array}{c}0.392 \\
(7.123) \\
\end{array}$ & $\begin{array}{c}-0.020 \\
(-0.372) \\
\end{array}$ & $\begin{array}{c}0.064 \\
(1.479) \\
\end{array}$ & $\begin{array}{c}0.126 \\
(2.676) \\
\end{array}$ & $\begin{array}{c}0.018 \\
(2.370) \\
\end{array}$ & 34.676 \\
\hline 25-CW Portfolios & Intercept & ב XMKT & SMB & HML & $C S V^{E W}$ & $R^{2} R^{2}(\%)$ \\
\hline $\begin{array}{c}\gamma \\
\text { tstat }\end{array}$ & $\begin{array}{c}0.465 \\
(7.574)\end{array}$ & $\begin{array}{c}-0.107 \\
(-1.685)\end{array}$ & $\begin{array}{c}0.078 \\
(1.587)\end{array}$ & $\begin{array}{c}0.134 \\
(2.634)\end{array}$ & $\begin{array}{c}0.025 \\
(1.730)\end{array}$ & 59.604 \\
\hline
\end{tabular}




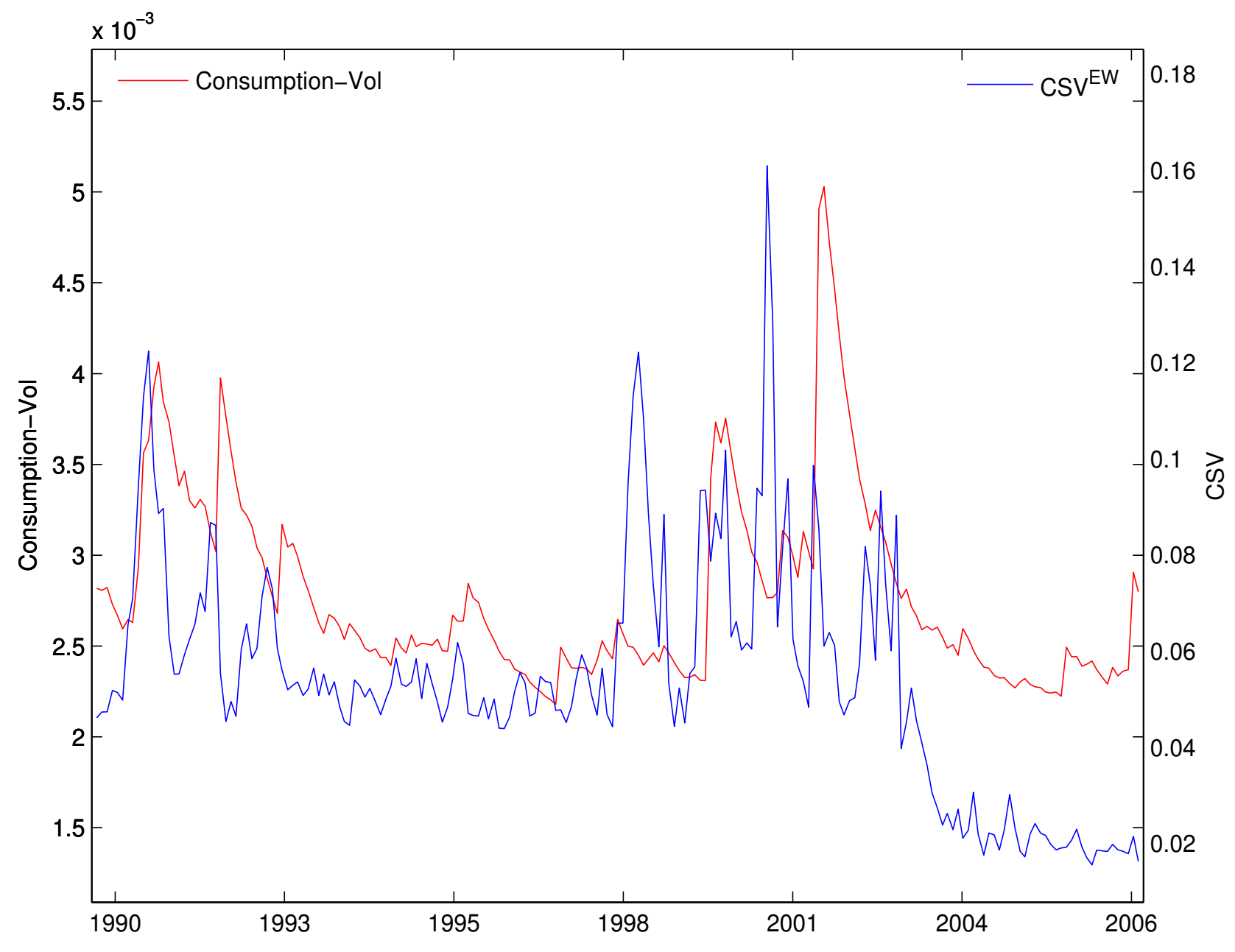

Figure 1: Cross-sectional Variance and Consumption Volatility: Monthly time series of $C S V^{E W}$ on the right-hand axis and Consumption Volatility on the left-hand axis. The sample period is January 1990 to December 2006. 